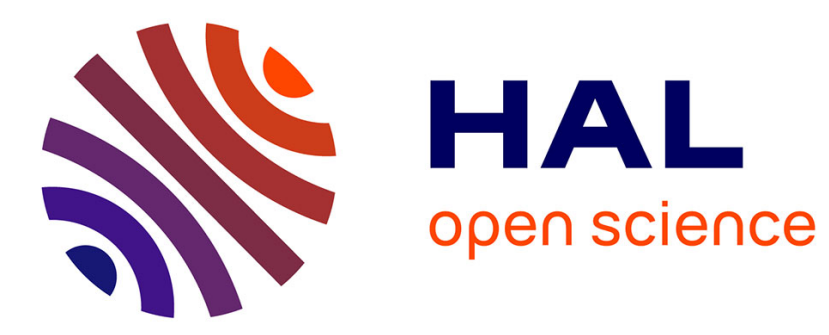

\title{
Challenges of microsatellite isolation in fungi
}

Christian Cyril Dutech, Jerome J. Enjalbert, Elisabeth E. Fournier, François

F. Delmotte, Benoît Barres, Jean Carlier, Didier Tharreau, Tatiana Giraud

\section{To cite this version:}

Christian Cyril Dutech, Jerome J. Enjalbert, Elisabeth E. Fournier, François F. Delmotte, Benoît Barres, et al.. Challenges of microsatellite isolation in fungi. Fungal Genetics and Biology, 2007, 44 (10), pp.933-949. 10.1016/j.fgb.2007.05.003 . hal-02667556

\section{HAL Id: hal-02667556 https://hal.inrae.fr/hal-02667556}

Submitted on 31 May 2020

HAL is a multi-disciplinary open access archive for the deposit and dissemination of scientific research documents, whether they are published or not. The documents may come from teaching and research institutions in France or abroad, or from public or private research centers.
L'archive ouverte pluridisciplinaire HAL, est destinée au dépôt et à la diffusion de documents scientifiques de niveau recherche, publiés ou non, émanant des établissements d'enseignement et de recherche français ou étrangers, des laboratoires publics ou privés. 


\section{Accepted Manuscript}

Challenges of microsatellite isolation in fungi

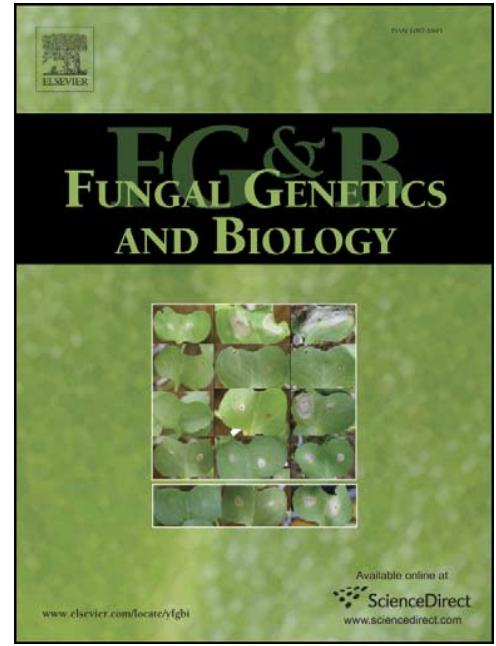

Cyril Dutech, Jérome Enjalbert, Elisabeth Fournier, François Delmotte, Benoit Barrès, Jean Carlier, Didier Tharreau, Tatiana Giraud

PII:

S1087-1845(07)00108-9

DOI:

10.1016/j.fgb.2007.05.003

Reference:

YFGBI 1863

To appear in:

Fungal Genetics and Biology

Received Date: $\quad 11$ October 2006

Revised Date: $\quad 4$ May 2007

Accepted Date: $\quad 28$ May 2007

Please cite this article as: Dutech, C., Enjalbert, J., Fournier, E., Delmotte, F., Barrès, B., Carlier, J., Tharreau, D., Giraud, T., Challenges of microsatellite isolation in fungi, Fungal Genetics and Biology (2007), doi: 10.1016/j.fgb. 2007.05.003

This is a PDF file of an unedited manuscript that has been accepted for publication. As a service to our customers we are providing this early version of the manuscript. The manuscript will undergo copyediting, typesetting, and review of the resulting proof before it is published in its final form. Please note that during the production process errors may be discovered which could affect the content, and all legal disclaimers that apply to the journal pertain. 


\section{Challenges of microsatellite isolation in fungi}

\section{CYRIL DUTECH $^{1}$, JÉROME ENJALBERT ${ }^{2}$, ELISABETH FOURNIER ${ }^{3}$, FRANÇOIS} DELMOTTE $^{4}$, BENOIT BARRÈS ${ }^{5}$, JEAN CARLIER $^{6}$, DIDIER THARREAU ${ }^{6}$, and TATIANA GIRAUD ${ }^{7}$

$7 \quad{ }^{1}$ INRA, Biodiversité, Gènes et Communautés, 33612 Cestas, France

${ }^{2}$ INRA, Laboratoire de Pathologie Végétale, 78850 Thiverval Grignon, France

${ }^{3}$ INRA, Phytopathologie et Méthologie de la Détection Versailles, Route de Saint Cyr, 78026

10 Versailles, France

${ }^{4}$ INRA, Santé Végétale, BP 81, 33883 Villenave d'Ornon, France

${ }^{5}$ INRA, Interactions Plantes-Microorganismes, 54280 Champenoux, France

${ }^{6}$ Biologie et Génétique des Interactions Plantes-Parasites, CIRAD-INRA-AGRO.M, TA 41/K, 34398 Montpellier, France

${ }^{7}$ Ecologie, Systématique et Evolution CNRS- Université Paris-Sud, Bâtiment 360, Université

16 Paris-Sud, 91405 Orsay, France

Keywords: SSR, plant pathogen, polymorphic markers, development, isolation, features affecting polymorphism

Running title: Fungal microsatellites

Corresponding author: Cyril Dutech. INRA, UMR 1202 BIOGECO, Equipe de Pathologie Forestière, Domaine de la Grande Ferrade, BP81, 33883 Villenave d'Ornon Cedex, France cdutech@bordeaux.inra.fr Tel: +33557122624. Fax: +33 557122621 


\section{Abstract}

2

Although they represent powerful genetic markers in many fields of biology,

3 microsatellites have been isolated in few fungal species. The aim of this study was to assess

4 whether obtaining microsatellite markers with an acceptable level of polymorphism is

5 generally harder from fungi than in other organisms. We therefore surveyed the number,

6 nature and polymorphism level of published microsatellite markers in fungi from the literature

7 and from our own data on seventeen fungal microsatellite-enriched libraries, and in five other

8 phylogroups (angiosperms, insects, fishes, birds and mammals). Fungal microsatellites indeed

9 appeared both harder to isolate and to exhibit lower polymorphism than in other organisms.

10 This appeared to be due, at least in part, to genomic specificities, such as scarcity and

11 shortness of fungal microsatellite loci. A correlation was observed between mean repeat

12 number and mean allele number in the published fungal microsatellite loci. The cross-species

13 transferability of fungal microsatellites also appeared lower than in other phylogroups.

14 However, microsatellites have been useful in some fungal species. Thus, the considerable

15 advantages of these markers make their development worthwhile, and this study provides

16 some guidelines for their isolation.

17

18

19 


\section{Introduction}

Microsatellite loci, short tandemly repeated motifs of 1-6 bases, also known as simple sequence repeats (SSR), are widely used as genetic markers because of their ubiquity, ease to score, co-dominance, reproducibility, assumed neutrality and high level of polymorphism (Jarne and Lagoda, 1996). They have proved to be invaluable in many fields of biology, from genome mapping to forensics, paternity testing and population genetics (Jarne and Lagoda, 1996; Luikart et al., 2003). Their interest to biologists goes beyond their high polymorphism: when one can assume a model for their evolution, taking into account the number of repeats allows inference of kin relationships among alleles, and they can thus be developed as powerful tools for inferring evolutionary and demographic parameters (Cornuet et al., 1999; Luikart et al., 2003; Michalakis and Excoffier, 1996). The major drawback of microsatellite loci is that they often need to be isolated de novo from each species, which can be timeconsuming and expensive. Cross-amplification, i.e. amplification of loci from a species other than the one in which they were cloned, is generally possible only among species of the same genera, and even in this case the percentage of cross-amplification is low (Rossetto, 2001). Furthermore, cross-amplification often generates null alleles which can bias genetic analyses (Hardy et al., 2003). In species for which no microsatellite markers for related species are available or cross-amplifiable, recently developed techniques, especially those involving enrichment of genomic DNA in microsatellites (Zane et al., 2002), have rendered the step of microsatellite isolation less laborious and more likely to succeed. However, the task of developing a working primer set from an enriched library can also represent a significant workload (Squirrell et al., 2003).

Microsatellites have been isolated across a wide range of taxonomic groups, but surprisingly little in fungi (Zane et al., 2002; Fig. 1). The low number of population geneticists interested in fungi compared to other organisms certainly explains this rarity, in 
1 addition to a preference for anonymous markers such as random amplified polymorphic DNA

2 markers (RAPD), amplified fragment length polymorphisms (AFLP) and inter-simple

3 sequence repeats (ISSR). These markers have only two alleles per locus, but they are easy to

4 develop in large numbers without the fastidious step of building a genomic library, and they

5 generally yield enough polymorphism to differentiate individuals within populations.

6 However, for some fungal species, their lack of species specificity can represent a serious

7 problem. For instance in fungal pathogens, DNA of the focal species can be difficult to isolate

8 from those of the host and of hyperparasites (e.g. mycoparasites; Kiss, 1998), thus requiring

9 an in vitro isolation step. Another drawback of AFLP, RAPD and ISSR is dominance, which

10 prevents the detection of heterozygotes in diploid species. Finally, even for haploid species

11 convenient for in vitro culture, the problem of anonymity remains, which can introduce

12 serious bias in population genetic studies. Indeed, different alleles from a single locus cannot

13 be easily recognized and markers with occasional non Mendelian behaviour, such as

14 transposable elements, are frequently amplified by these techniques. Amplification problems,

15 such as null alleles are easy to detect in microsatellites, and as minute amounts of template are

16 required, culture can be bypassed.

17 In addition to the low number of population studies on fungi and the preference for

18 anonymous markers, some peculiar biological and genomic traits of fungi may have limited

19 the number of polymorphic microsatellite loci isolated from genomic libraries. First,

20 pathogens which are the most extensively studied species within fungi, have demographic and

21 reproductive traits promoting a low genetic diversity. Crop or human pathogens have for

22 instance often experienced recent bottlenecks, through geographical introduction (Engelbrecht

23 et al., 2004; Milgroom et al., 1992; Rivas et al., 2004) or host shifts (Mackenzie et al., 2001;

24 Paraskevis et al., 2003; Tobler et al., 2003), which can drastically reduce intraspecific genetic

25 diversity. Furthermore, some specific life history traits of fungal pathogens, such as frequent 
1 asexual reproduction and recurrent bottlenecks in epidemic cycles, associated with low winter

2 survival and/or selective sweeps following new virulence attributes, are also likely to result in

3 low level of genetic diversity (Goodwin et al., 1994; Guérin and Le Cam, 2004; Hovmøller et

4 al., 2002). Second, fungal genomes may exhibit some peculiarities. Several recent papers

5 have examined the nature and abundance of microsatellites in published partial or complete

6 fungal genomes (Field and Wills, 1998; Karaoglu et al., 2005; Lim et al., 2004).

7 Microsatellites indeed appeared less abundant in these fungal genomes than in other

8 organisms (Morgante et al., 2002; Tóth et al., 2000), had different most abundant motifs

9 (Morgante et al., 2002; Tóth et al., 2000) and long loci were under-represented (Karaoglu et

al., 2005; Lim et al., 2004). Lim et al. (2004) reported that ca. $90 \%$ of microsatellite loci in 14

11 fungal genomes had low numbers of repeats, i.e. below eight. Long microsatellites, with high

12 numbers of perfect repeats, are more likely than short ones to be polymorphic because of a

13 higher rate of DNA replication slippage or unequal crossing-overs. Several studies have

14 indeed shown that the number of repeats is a good predictor of the level of variability in other

15 organisms (e.g. Brinkmann et al., 1998; Goldstein and Clark, 1995; Thuillet et al., 2002;

16 Vigouroux et al., 2002; Wierdl et al., 1997). If this correlation holds in fungi, most of their

17 microsatellites are expected to exhibit a low polymorphism. Furthermore, most of the

18 microsatellite loci detected in the published fungal genomes (94\%) are mononucleotide

19 repeats (Lim et al., 2004) that are seldom used in population genetics because of difficulties in

20 scoring alleles separated by single base pairs. The shortness of microsatellite loci in fungi,

21 their weak representation in the genomes, the low abundance of useful motifs, together with

22 the small size of fungal genomes (between 10 and $40 \mathrm{Mb}$ ), may limit the ability to find

23 numerous polymorphic microsatellite, even when a genomic library is available.

24 It is not entirely clear, however, whether the genomic and biological specificities listed

25 above are the major factors limiting the development of microsatellite markers in fungi. First, 
1 the conclusions drawn from these genomic studies are limited by the low number of complete

2 fungal genomes available, especially as a huge variability has been found among closely

3 related species in the number and nature of microsatellites (Ellegren, 2004; Karaoglu et al.,

4 2005; Lim et al., 2004). A survey of microsatellite development studies in different fungal

5 species would allow determination whether microsatellites are indeed generally difficult to

6 isolate and are particularly short. Second, another important limitation of genome analyses is

7 the lack of polymorphism assessment, which is the most valuable information for population

8 geneticists. Estimations of demographic or genetic parameters are indeed more powerful with

9 more polymorphic loci (e. g. Paetkau et al., 2004). If, for instance, microsatellite loci with

10 short repeats are reasonably polymorphic in fungi, their predominance in the genomes would

11 not be a problem for the development of useful markers. Comparing the degree of

12 polymorphism of microsatellites in fungi and in other organisms, and assessing whether the

13 correlation between the number of alleles and the number of repeats holds in fungi, are

14 therefore essential for determining whether attempts to develop microsatellites in this

15 kingdom are worthwhile given the investment required.

16 The aims of this paper were therefore to assess the yield of microsatellites from enriched libraries in fungi and to compare the polymorphism of isolated fungal microsatellites to that of other organisms, in order to determine whether obtaining microsatellite markers with an acceptable level of polymorphism is generally harder in fungi than in other organisms. The specific objectives of this paper were thus to (1) assess the yield of our own

21 seventeen microsatellite-enriched libraries, through the different steps, to identify which steps

22 limited the isolation of polymorphic loci; our data are free from publication bias, whereas

23 failures to develop polymorphic markers are rarely published; (2) estimate the general yield of

24 published microsatellite development in fungi; (3) evaluate the possibility of cross-

25 transferability of microsatellites among fungal species, which may represent an alternative to 
1 the fastidious development of a genomic library; (4) assess whether there is a correlation

2 between length and allele number among fungal microsatellites; (5) compare the nature, in

3 particular the size, of fungal microsatellites and their level of polymorphism to those of other

4 groups of organisms. In this study, we considered fungal species sensus lato, i.e. including

5 Oomycota, because these organisms share similarities with true fungi in their morphology and

6 life cycles, and many are also responsible for destructive plant diseases (Tyler, 2001).

\section{Material and methods}

\section{Enriched libraries}

The methods used to isolate our microsatellite loci were adapted from two protocols using oligoprobes for the enrichment of genomic libraries. The principle of both methods is the hybridization of restricted genomic DNA on microsatellite oligoprobes, followed by the washing of the non-hybridized genomic fragments. The first protocol, adapted from Edwards et al. (1996), uses membranes on which microsatellite oligoprobes are fixed. The second method is very similar, but uses streptavidin-coated magnetic beads on which biotin-labelled microsatellite oligoprobes are linked. Genomic fragments containing microsatellites hybridize with the oligoprobes, whose biotin links to the streptavidin of the magnetic beads. A magnet therefore allows retention of mostly DNA fragments with microsatellite loci (Kijas et al., 1994). The first method, with a membrane, was used for the species Cryphonectria parasitica (Breuillin et al., 2006), Erysiphe alphitoides (unpublished data) and Melampsora laricipopulina (Barrès et al., 2006). The bead method was used in addition for E. alphitoides and M. larici-populina, and for the 14 other species: Erysiphe necator (unpublished data), Fusarium culmorum (Giraud et al., 2002b), Fusarium poae (unpublished data), Magnaporthe grisea (Kaye et al., 2003), Microbotryum violaceum (Giraud et al., 2002a), Microcyclus ulei 
1 (Le Guen et al., 2004), Mycosphaerella eumusae (unpublished data), Mycosphaerella fijiensis

2 (unpublished), Mycosphaerella musicola (unpublished data), Penicillium camembertii

3 (unpublished data), Penicillium roqueforti (unpublished data), Plasmopara viticola (Delmotte

4 et al., 2006), Puccinia triticina (Duan et al., 2003) and Puccinia striiformis fsp tritici

5 (Enjalbert et al., 2002). For some species, several libraries had to be produced because of the

6 poor yield of the first one(s).

Twelve out of 17 librairies (70\%) were enriched for dinucleotide loci using (AC/TG) and $(\mathrm{AG} / \mathrm{TC})_{\mathrm{n}}$ oligoprobes, with $\mathrm{n}=10$ or 15 (Table 1$)$. The five other librairies were

9 enriched using only $(\mathrm{AC})_{10}$. These two dinucleotide motifs were chosen for enrichment because they had generally been reported as the most frequent in complete fungal genomes (e.g. Lim et al., 2004). Ten librairies were also enriched with trinucleotide motifs (mainly $(\mathrm{AAG})_{10}$; Table 1).

For each of our enriched libraries, we recorded: (1) the percentage of positive clones,

14 (2) the percentage of redundant sequences, i.e. of identical sequences, (3) the percentage of contaminant clones, i.e. with a significant BLAST value towards a sequence from another

16 species, (4) the percentage of unique sequences, excluding contaminants, with a microsatellite locus (tandemly repeated motifs of 1-6 bases with at least 5 pure repeats, according to the most common definition; Ashley and Dow, 1994 ; Lim et al., 2004), (5) the percentage of unique sequences, excluding contaminants, with a microsatellite locus and suitable flanking regions, (6) the percentage of sequences yielding loci with a clear amplification, (7) the

21 percentage of sequences yielding polymorphic loci at the intra-population level and (8) the 22 percentage of sequences yielding polymorphic loci at the largest measured scale (from interpopulation to inter-continental levels, or between populations from different host species). All

24 the above percentages were estimated as ratios over the number of inserts correctly 25 sequenced, except the percentage of positive clones, which was estimated over the total 
1 number of clones with inserts. When several libraries had been built for one species, the

2 average yield was taken for each step. In addition, we recorded for each polymorphic locus:

3 (1) The base composition of the microsatellite motif (2) its perfection (a locus was considered

4 as imperfect if the tandem repeats were interrupted or if several different tandem repeats with

5 more than five repeats each were amplified as a single locus), and (3) the number of tandem

6 repeats (for imperfect loci, number of repeats of the longest perfect microsatellite). The

7 number of repeats was recorded from the sequenced fragment obtained in the library. Finally,

8 we estimated genetic diversity of microsatellite loci as the number of alleles at the largest

9 scale (spatially or inter-hosts). We also recorded the sample size used for assessing

10 polymorphism.

\section{Literature search and data extraction}

To find studies reporting the development of microsatellite markers in fungi, we

searched the bibliographic data bases Web of Knowledge (http://isi4.newisiknowledge.com/) and Pubmed (http://www.ncbi.nlm.nih.gov/entrez/query.fcgi) from January 1985 to June 2006 for all papers with "microsat* and fung* and (isol* or clon* or characteri*)" and "SSR and fung* and (isol* or clon* or characteri*)" in the title, keyword or abstract. We included all data from all papers to which we had access, regardless of the method of microsatellite isolation, except that we kept a single study per species and only the studies having isolated at 20 least two polymorphic dinucleotide loci for comparison between species (see below). For 21 each locus, we recorded the following information when available (1) the length and base 22 composition of the motif, (2) its perfection, (3) the number of repeats of the longest perfect microsatellite (4) the sample size used for assessing polymorphism, (5) the number of alleles.

24 We also recorded the number of loci for which primers could be designed, the percentage of 25 scorable loci and the percentage of polymorphic loci per species, when available. 
1 In addition, cross-species transferability of microsatellite markers in fungi was

2 evaluated from published studies and our own data. We kept 20 studies for which one source

3 species could be clearly identified and data on cross-species transferability was available

4 within a genus, data at lower or higher taxonomic levels being scarce in fungi. In total, 24

5 source species, 88 target species and 302 primer pairs were tested across these studies. For

6 each target species, a primer pair was considered as transferable when a PCR product of

7 expected size was obtained in at least one individual. We computed the transferability as the

8 mean percentage of loci that were transferable to other species. those of other organisms, we searched issues of Molecular Ecology Notes from March 2001

11 to June 2005 for studies reporting isolation of microsatellites in angiosperms, insects, fish (restricted here to Actinopterygii), birds and mammals. These different phylogenetic groups ('phylogroups' hereafter) were chosen to span a wide range of living species and to include at

14 least 50 studies, i.e. a number similar to that of published studies in fungi. We counted the number of primer notes for each phylogroup, and for the 50 most recent, we recorded for each polymorphic dinucleotide locus with a minimum of 5 repeats, the same items as for the fungal

17 bibliographic data above. A few studies had to be discarded because they reported less than two polymorphic dinucleotide markers. The complete dataset included 2,923 microsatellite

\section{Data analyses} compared 1) the yield of the different steps of microsatellite isolation, 2) the mean repeat number, and 3) the mean allele number per locus and per species, between our dataset and the 
1 isolated motifs in librairies) were retained to remove any possible effect of the length of the

2 motif on allelic diversity.

3 To analyse the effect of the phylogroup (i.e. fungi, angiosperms, fishes, insects, birds

4 or mammals) on the mean repeat number and on the mean allele number per species,

5 unpublished studies on fungi were discarded and only polymorphic dinucleotide loci were

6 retained, in order to have data similar to the other phylogroups. The phylogroup effect was

7 tested using an analysis of variance, with the GLM procedure of the SAS software (SAS

8 Institute, SAS Publishing, Cary, NC). Variables were Log-transformed for the residuals to

9 reach normality. Pairwise mean comparisons among phylogroups were performed using

10 Student-Newman-Keuls tests (SNK; Means option in GLM, SAS software). For the mean

11 number of alleles per species, we retained only the studies with a minimum of 14 genotyped

12 individuals to reduce the bias of a too small sample size.

13 The effects of the imperfection, the motif (CA/GT vs GA/CT, the other dinucleotides

14 being too rarely isolated), the number of repeats, the sample size and the species on allele

15 numbers were assessed using a generalized linear model (GENMOD procedure of SAS),

16 assuming a Poisson distribution and a log-link function. Because the "allele" variable was

17 over-dispersed, a scaling parameter was calculated to improve the fit to the Poisson

18 distribution. Full models were first fitted including all factors and all interactions, and then

19 simplified by sequential removal of the least significant highest-order interaction term,

20 retaining significant interactions and all main effects, even when non-significant.

21

Results 
1 In preliminary experiments, we tried to clone fungal microsatellites without

2 enrichment in two species ( $P$. striiformis fsp triti and $P$. triticina). The yield was so low (ca.

$30.5 \%$ of positive clones) that enrichment appeared unavoidable. In our enriched libraries

4 where the clones were screened for the presence of microsatellites, the mean percentage of

5 positive clones $( \pm$ SE) was $20.2 \%( \pm 5.2)$. Five libraries had more than $30 \%$ of positive

6 clones and four had fewer than $6 \%$.

8 First, a non negligible number of redundant clones were recovered in all experiments,

9 probably due to the two PCR steps required for enrichment: the average number of sequences

10 identical to previous sequences had a mean $( \pm \mathrm{SE})$ of $26.2 \%( \pm 5.1)$. Second, in three

11 laboratories, contamination by foreign DNA occurred in six species (P. roqueforti, $P$.

12 camemberti, F. poae, $P$. viticola, M. larici-populina and C. parasitica) and could reach up to

$1369 \%$ of the sequences. These contaminant sequences were easily identified: they were

14 repeated several times in the libraries, blasted significantly to sequences in public databases,

15 and/or were sequenced in the previous enrichments performed in the same laboratory. Third,

16 problems in sequencing were met in most of the libraries, in several different laboratories,

17 using either DNA extracted from clones or PCR products purified with various commercial

18 kits. The failure of sequencing reactions seemed to be specific to our adaptors, $M l u \mathrm{I}$ (Edwards

19 et al., 1996), that may adopt a particular 3D structure when linked into vectors from the Topo

20 TA Invitrogen kit, impeding sequencing reactions. The problems in sequencing may also be

21 due to the presence of identical adaptors at each end of the insert. Proper sequences could

22 only be obtained using a particular protocol of PCR product purification, using PEG

23 (Rosenthal et al., 1993). Other studies have used adaptors encompassing a restriction site to

24 avoid this problem (Armour et al., 1994; Tenzer et al., 1999). 
In our 17 enriched libraries, the average percentage $( \pm \mathrm{SE})$ of unique sequences,

2 excluding contaminants, having a microsatellite locus of at least five perfect repeats

3 (Appendix 1) was only $55.4 \%( \pm 4.6)$ of the correctly sequenced inserts. Among those, the

4 percentage of useful sequences consistently and sharply decreased along the different steps of

5 the experiment (Fig. 2). The mean ( \pm SE) of the number of loci eventually polymorphic at the

6 intra-population scale was only of $9.6 \%( \pm 2.5)$. One of the most critical steps was the

7 suitability of the sequences for primer design (mean \pm SE of $56.9 \% \pm 6.2$ of unique

8 sequences with a microsatellite), due to flanking regions with unsuitable base composition or

9 length, or to microsatellites with too few perfect repeats. The percentage of amplified loci

among those suitable for primer design was generally high (mean \pm SE of $68 \% \pm 8.2$ ),

11 although it was very low in some species. In E. alphitoides, E. necator, F. poae, M. larici-

populina, and $P$. viticola, less than $45 \%$ of the loci retained for primer design could actually

be amplified (Appendix 1). The second most important source of attrition was the level of

polymorphism obtained from amplifiable loci : the percentage of sequences that eventually

yielded polymorphic loci ranged from 0 to $50 \%$ of the initial number of sequenced clones,

with only five species above $20 \%$ at the inter-population level (Appendix 1 ) and a mean ( \pm

SE) of $17.2 \%( \pm 3.5)$ (Fig. 2). The intra-population level of polymorphism was even lower,

with a mean $( \pm \mathrm{SE})$ of $9.6 \%( \pm 2.7)$ of polymorphic loci (Fig. 2$)$. In four species (the two

Puccinia spp. and the two Penicillium spp.), no polymorphic loci at all could eventually be

20 recovered at the intra-population scale (Appendix 1).

21 It was not possible to test here if the method of enrichment (membrane versus beads)

22 or the length of oligoprobes impacted on the yield of libraries, because the number of studies was too low and because microsatellite isolation was performed using different methods in too few species (Table 1). However, regardless of the method, the general trend was a poor 
1 were used (M. larici-populina and E. alphitoides), similar results were observed (data not

2 shown), suggesting a lack of protocol effect. There was also no indication that the libraries

3 enriched for both di- and trinucleotides had a better yield than the libraries enriched only for

4 dinucleotides (means of $17 \%( \pm 4.9)$ and $14 \%( \pm 4.3)$ of polymorphic loci isolated,

5 respectively). For four out of the ten species enriched with a trinucleotide oligoprobe, no

6 polymorphic trinucleotide loci could be isolated, and for three of them a single polymorphic

7 locus was recovered (data not shown). The mean percentage of polymorphic loci at the largest

8 scale seemed to be slightly higher in the five genomic libraries enriched using only $(\mathrm{AC})_{10}$

9 than in those enriched using both $(\mathrm{AC} / \mathrm{TG})_{\mathrm{n}}$ and $(\mathrm{AG} / \mathrm{TC})_{\mathrm{n}}$ (means of $25 \%$ and $12 \%$

respectively; Appendix 1), but there were too few studies to test this difference given the large

11 species effect (see below).

\section{Comparison between our dataset and the published studies in fungi}

other fungi to detect possible publication bias or specificities in our data. We collected data on microsatellite isolation from 37 fungal species from the literature (Table 1). Among these, 14 $\%$ used non-enriched libraries and $43 \%$ used beads or membranes to enrich libraries. The other methods of microsatellite isolation were based on ISSR (Burgess et al., 2001), FIASCO

19 (Zane et al., 2002), anchored PCR (Zane et al., 2002), and or searches in EST libraries

20 (Appendix 2). Despite the diversity of the methods of microsatellite isolation, the proportion

21 of polymorphic loci relative to the loci tested in fungal species was not significantly different

22 in the literature (mean $\pm \mathrm{SE}$ of $49.7 \pm 5.0 \%$ among the sequences for which primers were designed, Appendix 2) and in our dataset (53.2 $\pm 7.4 \%$; Mann-Withney's test, $\mathrm{Z}=-0.43, \mathrm{P}=$ $0.67)$. 
As in our libraries, most of the polymorphic loci in published studies on fungi were

2 dinucleotides (69\% and $88 \%$ for our data). Considering only the dinucleotide loci, the mean

3 number of repeats per locus and per species was similar in our dataset and in the published

4 studies $(11.1 \pm 0.7$ vs $11.9 \pm 0.8$; Mann-Withney's test, $\mathrm{Z}=0.11, \mathrm{P}=0.92)$. In the 22 studies

5 in which libraries were enriched for both the dinucleotides $(\mathrm{AC} / \mathrm{GT})_{\mathrm{n}}$ and $(\mathrm{AG} / \mathrm{CT})_{\mathrm{n}}$,

6 consistently more polymorphic microsatellites were isolated with AC repeats than with AG

7 repeats, regardless of the method of enrichment ( $5.3 \pm 1.3$ versus $2.8 \pm 0.8$ loci per species in

8 the published studies and $8.7 \pm 2.5$ versus $2.3 \pm 0.7$ in our data, for $(\mathrm{AC} / \mathrm{GT})_{\mathrm{n}}$ and $(\mathrm{AG} / \mathrm{CT})_{\mathrm{n}}$

9 loci respectively).

Cross-species transferability of microsatellite markers between fungal species

Cross-species transferability of microsatellite primer pairs in fungi was estimated

based on 24 studies from the literature and our own data. Only $34 \%$ of the 1045

species/primer pair combinations tested within genera were successful in amplifying bands of the expected size. Neither homology, polymorphism nor presence of null alleles in the transferred microsatellite markers were generally assessed.

\section{Comparison of fungal microsatellites with those of other organisms}

Only 53\% of the published loci were dinucleotides in birds, against ca. $70 \%$ in fungi and fish and more than $80 \%$ in plants, mammals and insects. More than $34 \%$ of the published

21 loci were tetranucleotides in birds, against less than 5\% in fungi, insects and plants. Comparison of the 46 published studies on fungal microsatellite development with at least two dinucleotide polymorphic loci and the 50 published Primer Notes on microsatellites isolated from angiosperms, birds, mammals, fish and insects, found no significant difference 
$1 \quad($ Kruskal-Wallis' test, $\mathrm{H}(5,292)=8.1, \mathrm{P}=0.15)$. The mean number of polymorphic loci per

2 species was not the lowest in fungi, with a mean \pm SE of $9.3 \pm 1.0$; the other phylogroups

3 ranging from $8.5 \pm 0.8$ (insects) to $13.6 \pm 3.4$ (fish).

The number of repeats per dinucleotide locus and per species had a significantly lower

5 mean in fungi $(11.8 \pm 0.7)$ than in all the other phylogroups except birds $(13.2 \pm 0.6)$. The

6 means of the other phylogroups ranged from 15.3 (insects) to 17.4 (mammals and fish)

7 repeats per locus per species (Fig. 3A). The mean number of alleles per species also had a

8 significantly lower mean in fungi $(5.4 \pm 0.4)$ than in all the other phylogroups (Fig. 3B). All

9 these phylogroups had similar means of number of alleles per species, ca. 8 alleles, except

10 fish that had a significantly higher mean (11.6 \pm 1.2 ; Fig. 3B).

\section{Factors affecting the diversity of dinucleotide microsatellites}

In fungi, the correlation between the mean repeat number and the mean allele number

14 per species was marginally significant $(r=0.28, P=0.06$, Fig. 4$)$. The short loci indeed had a

15 very low level of polymorphism, whereas long loci had a larger range of allele numbers, their

16 polymorphism being high for some but still low for others. The mean repeat number and the

17 mean allele number per species were significantly correlated in birds $(r=0.72, \mathrm{P}<0.001)$,

18 insects $(\mathrm{r}=0.40, \mathrm{P}=0.007)$ and fish $(\mathrm{r}=0.32, \mathrm{P}=0.03)$, but not in mammals $(\mathrm{r}=0.07, \mathrm{P}=0.63)$ or

19 in angiosperms $(\mathrm{r}=0.19, \mathrm{P}=0.19)$. However, GENMOD analyses on the complete dataset with

20 all loci and taking into account the effects of the other parameters (see below) found the effect

21 of the number of repeats on the number of alleles significant in all the phylogroups, the

22 regression coefficients being consistently lowest in mammals and angiosperms.

A generalized analysis of variance was performed to further investigate which

parameters influenced the diversity of individual microsatellite dinucleotide loci in fungi, 
1 species (Table 2). The main source of variation affecting the number of alleles of

2 microsatellites was the differences among species. A significant effect of the number of

3 repeats was also detected, whereas sample size, imperfection and motif were not significant.

4

5

\section{Discussion}

Consistent problems were met when isolating microsatellite loci from different fungal species. First, the yield of enriched libraries (percentage of positive clones) was low, mostly less than $30 \%$. This percentage is at the lower limit of what has been obtained from other groups of organisms using the same protocols of microsatellite enrichement, which usually leads to $20 \%$ - $90 \%$ of positive clones (Zane et al., 2002). Second, the attrition along the different steps from positive clones to polymorphic loci was very high (mean \pm SE of $83.8 \%$ \pm 3.2). This attrition level is similar to that found in plants, which are known to be recalcitrant species for isolating microsatellite markers (Squirrell et al., 2003). For both fungi and plants, the percentage of loci suitable for primer design and the percentage of polymorphic loci seem to be the two most critical steps in microsatellite development. The low percentage of loci suitable for primer design, both in our data and the literature, is partly due to the choice of discarding loci with less than eight perfect repeats. The reason for disregarding them was that very low polymorphism, if any, is generally expected for such short microsatellites. The low polymorphism of short loci observed in fungi, and the positive correlation between number of repeats and number of alleles in fungal species, validated this choice. The final mean percentage of the initial non redundant sequences containing a polymorphic microsatellite at the intra-population level was less than $10 \%$. In several fungal species, no polymorphic loci at 
1 all could be found polymorphic at the within-population level, precluding any estimation of

2 population genetics parameters, such as mode of reproduction or level of gene flow.

3

4

In addition to the established redundancy of sequences in enriched libraries (Squirrell

et al., 2003), several of our libraries had high rates of contaminant sequences and/or a low success of primer amplification; in particular in P. viticola, M. larici-populina, E. alphitoides, E. necator, $P$. roqueforti, $P$. camemberti, and $F$. poae. In the cases of $P$. roqueforti, $P$. camemberti and $F$. poae, contamination was clearly due to the enrichment protocol, involving several PCR steps, because contaminant sequences were from $M$. violaceum which had previously been enriched for microsatellites in the same laboratory. Contaminations by the host DNA, bacteria or saprophytic fungi may explain the lack of amplification with tested primer pairs for the obligate pathogens $P$. viticola, E. alphitoides, E. necator and M. larici-populina. The contamination problems may be exaggerated in obligate pathogens by the small quantity of DNA that can be obtained after cultivation on their host, which favours the amplification of foreign DNA during the enrichment steps.

Published studies on microsatellite development from fungi experienced the same difficulties as our work, regardless of the method used. The yield of libraries was consistently low, both in terms of quantity and quality of loci isolated, with a few exceptions. It is likely that many attempts to develop microsatellite in other fungal species have never been published because the number of polymorphic loci isolated is too low, as was the case for our libraries: only nine of our 17 microsatellite developments have been published, five of the eight unpublished libraries having yielded each fewer than three loci polymorphic at the intrapopulation level. The proportion of polymorphic loci relative to the number of loci tested and the mean number of alleles per locus in fungi may therefore be yet lower than suggested by this survey. 
Specific difficulties in developing fungal microsatellites were further revealed when

2 comparing microsatellites to those isolated in other organisms. The mean number of loci

3 isolated from fungi was similar to that of birds or insects, but they were significantly shorter

4 in fungi than in other phylogroups, except birds. This difference was even stronger when

5 considering all published microsatellites, i.e. with fewer than five repeats, which were not

6 included in our study according to our microsatellite definition. These very short

7 microsatellites represented almost $15 \%$ of all the published loci in fungi, against less than $5 \%$

8 in the other phylogroups. Despite a preference for loci with the highest numbers of repeats,

9 generally assumed to be the most polymorphic, the scarcity of long microsatellites in the

10 fungal libraries has certainly constrained the choice towards very short microsatellites. The

11 methods used to isolate microsatellites in fungal species may have affected the statistics of the

12 cloned loci, in particular their length. However, most of the methods used in fungi were also

13 used in the other phylogroups (Zane et al., 2002); enrichments with beads or membranes

14 being prominent in all the groups. Despite the noise that the different methods of isolation

15 may have introduced, the present literature survey based on more than 2200 dinucleotide loci

16 and 250 species showed that microsatellite loci isolated from fungal species had both

17 significantly fewer repeats and fewer alleles than those from the other phylogroups examined.

18 In addition, our study showed that there is little to expect from cross-species

19 transferability of microsatellites in fungi. Within genera, only $34 \%$ of the loci tested could be

20 transferred, which appears much lower than in animals or plants. In plants for instance, 76.4

$21 \%$ of 1800 species/primer combinations tested within genera were successful (Rossetto,

22 2001). This discrepancy may be due to higher levels of sequence divergence between fungal

23 species within genera in comparison to animals and plants. In fact, the percentage of protein

24 identity between three fungal species belonging to the genus Aspergillus has been found to be

25 comparable to that between mammals and fish (i.e. 66 to $70 \%$; Galagan et al., 2005). This 
1 lower transferability in fungi compared to other organisms suggests that the need to build a

2 specific library for each species to be studied is even more crucial in fungi.

3

4

A first explanation for the low number and the lack of diversity of microsatellite loci in fungi is linked to the genomic specificities of these organisms. A general low density of microsatellites has been found in the complete fungal genomes available (Morgante et al., 2002; Tóth et al., 2000) as well as a rarity of long motifs (Lim et al., 2004; Karaoglu et al, 2005). Both the low density and the shortness of microsatellites should lower their propensity to hybridize on the probes used for enrichment. Furthermore, the positive correlation between microsatellite polymorphism and number of repeats in perfect tandem was shown to hold in fungi. Therefore, the general shortness of microsatellites in fungal genomes should not only impact on the number of isolated loci, but also, and more importantly, on their level of polymorphism. So far, we do not have any strongly supported explanation for the low density and the low level of repeat number observed in fungal microsatellites. It should, however, only depend on genomic processes limiting the number and the size of microsatellites but not on other fungal specificities such as life history traits. Measures of mutation rates, greatly facilitated in fungi by their asexual reproduction and rapid generation times, would be valuable for assessing the existence of an efficient mismatching repair system in fungi that limits expansion of microsatellites, as suggested by Karaoglu et al. (2005).

Restricted sampling design may also be invoked to explain the low polymorphism of fungal microsatellites. However, we recorded the results of fungal diversity from the largest spatial scale tested in each study, we retained only the studies with more than 14 strains, and the sampling scheme was often chosen to maximise diversity by testing the loci on populations that were as different as possible, i. e. from different countries or continents, or from different host species. There was no indication that the sample scale in fungi was less 
1 representative of species diversity than that in the other phylogroups. The analysis of variance

2 furthermore confirmed that the effect of sampling size on diversity was not significant in our

3 survey.

In addition to genomic characteristics, i.e. shortness of loci, the lower polymorphism

5 observed in fungal microsatellites compared to those in other phylogroups may be due to

6 some specificities of their life-history traits or history. For instance, the species in which long

7 microsatellites (i.e. higher than 12 perfect repeats in average) have been found but that

8 exhibited a mean diversity lower than five alleles per locus were generally pathogens on few

9 cultivated plants, or were recently introduced (e.g. Ascochyta rabei, Cryphonectria parasitica,

10 Magnaporthe grisea, Microcyclus ulei, Mycosphaerella fijiensis, M. musicola, Paecilomyces

11 fumosoroseus, Phytophtora infestans). These results are consistent with reduced diversity in

12 these species being due to bottlenecks following introductions and/or recent host shifts, as

13 may be the case in many studied fungi. However, additional analyses are required because the

14 diversity in the life-history traits and in the population history of the species precluded

15 detailed analyses testing for their effects on microsatellite polymorphism.

17 Although the overall yield of microsatellite development was generally low in fungi,

18 microsatellites have been isolated and have proven to be polymorphic within populations in a

19 few species. In fact, the main factor explaining the level of polymorphism among fungal

20 species was the species identity. We could not identify clear factors explaining the high

21 polymorphism in certain species. The most polymorphic of our 17 species $(C$. parasitica, $F$.

22 culmorum, $M$. violaceum and $M$. mycosphaerella) were not necessarily those having the

23 highest numbers of sequenced clones, tested primer, of individuals sampled, or largest spatial

24 scales sampled, nor did they have any obvious peculiar history or reproductive mode. In $M$.

25 violaceum, the diversity was certainly over-estimated because of the existence of cryptic 
1 sibling species (Giraud et al. 2002a), but it does not seem to be the case in the other above

2 species. We could not find any obvious factors explaining the level of diversity per species in

3 the literature survey of fungal microsatellites either. Because there is no apparent rule, a good

4 strategy when deciding whether a microsatellite library is worth constructing may therefore be

5 to first evaluate the polymorphism of the species using other markers, such as AFLP, ISSR or

6 RAPD. Such methods do not require the investment that microsatellites do for development

7 and may serve as a preliminary test for the level of polymorphism in the focal species. For

8 instance, our own AFLP analyses conducted in parallel to the microsatellite ones on five

9 fungal species (Lopez-Villavicencio et al. 2005; Enjalbert et al. 2005; unpublished data)

10 indicated that when two individuals presented on average less than one band difference per

11 AFLP profile (using 2 selective bases on each primer), polymorphism was difficult to find

12 with microsatellites. We advocate that if AFLP on a given sample yields less than $2 \%$

13 difference between individuals per profile (i.e., one band difference on a profile with fifty

14 bands), microsatellites probably will not be polymorphic, and building enriched microsatellite

15 libraries may just be a waste of time and money. More efficient alternatives should then be

16 sought. For instance, polymorphism can be looked for in fragments generated by RAPD or

17 ISSR and specific primers can be developed such as sequence characterised amplified regions

18 (SCAR). Relative to a microsatellite library, this method is a rapid screen of putative

19 polymorphic loci. In addition, the rapid development of genomics may offer a new route for

20 efficiently developing powerful markers in fungi. In particular, expressed sequence tags or

21 extensive genomic libraries provide interesting material for finding long microsatellites (Kaye

22 et al. 2003; Breuillin et al. 2006) or other markers, such as single nucleotide polymorphim

23 (SNPs). 
1 If microsatellite development is to be performed, the present study provides some

2 guidelines. First, this survey points to the necessity of using enriched protocols for isolation of

3 microsatellite markers. Our rare attempts to directly clone microsatellites from total DNA

4 failed and $86 \%$ of the published microsatellite fungal isolations were performed using

5 enriched protocols or searches in databases. It was not possible to test the effect of the

6 methods of enrichment on the yield of libraries and on the polymorphism of the loci isolated,

7 although the rare studies using several methods on a single species gave no indication of any

8 differences. However, we found enrichment with beads more convenient than with

9 membranes. Furthermore, it is worth noting that the ISSR method, more specifically used in

fungi, seemed to preferentially isolate short microsatellites, but comparisons of several

11 methods of isolation on the same species are required to provide compelling evidence for such

12 a bias. Second, regarding the choice of motif for enrichment, AG appears the most frequent in

13 the published fungal genomes (Lim et al., 2004). In contrast, we found that in the studies in

14 which libraries were enriched for both the dinucleotides AC and AG, consistently more

15 polymorphic microsatellites were isolated with AC repeats than with AG repeats. However,

16 the analyses of fungal genomes also underlined a high variability among species regarding the

17 most frequent motifs, with several genomes with a low density of AG motif and higher levels

18 of AT (Lim et al., 2004). The AT motif should, however, be avoided as self-complementarity

19 makes this motif difficult to amplify, and the number of repeats is generally low (Karaoglu et

20 al., 2005). As it is difficult to decide a priori which motifs are the most abundant in a given

21 species, the best strategy may be to enrich for both the AC and AG motifs in order to increase

22 the probability to recover numerous and long loci. In addition, although our libraries did not

23 yield many useful trinucleotide markers, enriching libraries for trinucleotides may be worth

24 trying. Such motifs indeed represented $24 \%$ of all the polymorphic published loci in fungi.

25 Third, our analyses confirmed that, after species identity, the best predictor of polymorphism 
1 was the length of the longest perfect microsatellite. For developing polymorphic

2 microsatellites, loci with the highest number of perfect repetitions should therefore be the best

3 candidates. However, we found that it may be hard in many fungal species to isolate several

4 microsatellite loci with more than eight repeats. Many loci with five to seven repetitions were

5 polymorphic within populations in some fungal species, and those may thus be worth testing.

7 Acknowledgements

8 This study was funded by the REID (Réseau Ecologie des Interactions Durables),

9 INRA, CNRS and the Université Paris Sud. We thank Jacqui A. Shykoff, Philippe Jarne and

10 Barbara Hefti-Gautschi for helpful discussions and for comments on a previous version of the

11 manuscript and Bruno Le Cam, Marc Seguin and Marc-Henri Lebrun for sharing unpublished

12 data. We also thank the Genoscope, Evry, France for the sequencing of library clones from

13 Magnaporthe grisea, Microcyclus ulei, and Mycosphaerella spp. (project «Plantes et

14 parasites tropicaux - Recherche de locus microsatellites sur plusieurs espèces »). Hans

15 Lawton helped gathering literature data.

16

17

18

19

20

21

22

23

24

25

\section{References}

Armour, J., Neumann, R., Gobert, S. Jeffreys, A., 1994. Isolation of human simple repeat loci by hybridization selection. Hum. Mol. Genet. 3, 599-605.

Ashley, M.V., Dow, B.D., 1994. The use of microstellite analysis in population biology: Background, methods and potential applications. In: Schierwater, B., Streit, B., Wagner, G., DeSalle, R. (Eds.), Molecular Ecology and Evolution, Approaches and Applications. Birkäuser Verlag, Basel, pp. 185-201. 
1 Barrès, B., Dutech, C., Andrieux, A., Caron, H., Pinon, J., Frey, P. 2006. Isolation and characterization of 15 microsatellite loci in the poplar rust fungus, Melampsora laricipopulina, and cross-amplification in related species. Mol. Ecol. Notes 6, 60-64.

Breuillin, F., Dutech, C., Robin, C., 2006. Genetic diversity of the chesnut blight fungus Cryphonectria parasitica in four French populations assessed by microsatellite markers. Mycol. Res. 110, 288-296.

Brinkmann, B., Klintschar, M., Neuhuber, F., Huhne, J., Rolf, B., 1998. Mutation rate in human microsatellites: influence of the structure and length of the tandem repeat. Am. J. Hum. Genet. 62, 1408-1405.

Burgess, T., Wingfield, M., Wingfield, B., 2001. Simple sequence repeat markers distinguish among morphotypes of Sphaeropsis sapinea. App. Environ. Microbiol. 67, 354-362.

Cornuet, J.-M., Piry, S., Luikart, G., Estoup, A., Solignac, M., 1999. New methods employing multilocus genotypes to select or exclude populations as origins of individuals. Genetics 153, 1989-2000.

Delmotte, F., Chen, W.-J., Richard-Cervera, S., Greif, C., Papura, D., Giresse, X., MondorGenson, G., Corio-Costet, M.-F., 2006. Microsatellite loci from the grape downy mildew (Plasmopara viticola). Mol. Ecol. Notes. 6, 379-381.

Duan, X., Enjalbert, J., Vautrin, D., Solignac, M., Giraud, T., 2003. Isolation of twelve microsatellite loci, using an enrichment protocol, in the phytopathogenic fungus Puccinia triticina. Mol. Ecol. Notes 3, 65-67.

Edwards, K.J., Barker, J.H.A., Daly, A., Jones, C., Karp, A., 1996. Microsatellite librairies enriched for several microsatellite sequences in plants. Biotechniques 20, 758-760.

Ellegren, H., 2004. Microsatellites: Simple sequences with complex evolution. Nature Rev. Genet. 5, 435-445. 
1 Engelbrecht, C., Harrington, T., Steimel, J. Capretti, P., 2004. Genetic variation in eastern North American and putatively introduced populations of Ceratocystis fimbriata $f$. platani. Mol. Ecol. 13, 2995-3005.

Enjalbert, J., Duan, X., Vautrin, D., Giraud, T., Vallavieille Pope, C. de, Solignac, M., 2002. Isolation of twelve microsatellite loci, using an enrichment protocol, in the phytopathogenic fungus Puccinia striifomis f.sp. tritici. Mol. Ecol. Notes 2, 563-565.

Enjalbert, J., Duan X., Leconte M., Hovmøller M., Vallavieille-Pope., C. de, 2005. Genetic evidence of local adaptation of wheat yellow rust (Puccinia striiformis f. sp tritici) within France. Mol. Ecol. 14, 2065-2073.

Field, D., Wills, C., 1998. Abundant microsatellite polymorphism in Saccharomyces cerevisiae, and the different distributions of microsatellites in eight prokaryotes and $S$. cerevisiae, result from strong mutation pressures and a variety of selective forces. Proc. Natl. Acad. Sci. 95, 1647-1652.

Fisher, P., Gardner, R. Richardson, T., 1996. Single locus microsatellites isolated using 5' anchored PCR. Nuc. Acids Res. 24, 4369-4371.

Galagan, J.E., Calvo, S.E., Cuomo, C., Ma, L.J., Wortman, J.R., Batzoglou, S., Lee, S.I., Basturkmen, M., et al., 2005. Sequencing of Aspergillus nidulans and comparative analysis with A. fumigatus and A. oryzae. Nature 438, 1105-1115.

Giraud, T., Fournier, E., Vautrin, D., Solignac, M., Shykoff, J.A., 2002a. Isolation of 44 polymorphic microsatellite loci in three host races of the phytopathogenic fungus Microbotryum violaceum. Mol. Ecol. Notes 2, 142-146.

Giraud, T., Fournier, E., Vautrin, D., Solignac, M., Vercken, E., Bakan, B., 2002b. Isolation of eight polymorphic microsatellite loci, using an enrichment protocol, in the phythopathogenic fungus Fusarium culmorum. Mol. Ecol. Notes 2, 121-123. 
1 Goldstein, D., Clark, A., 1995. Microsatellite variation in North American populations of

2

3 Goodwin, S., Cohen, B., Fry, W., 1994. Panglobal distribution of a single clonal lineage of Drosophila melanogaster. Nuc. Acids Res. 23, 3882-3886. the Irish potato famine fungus. Proc. Natl. Acad. Sci. USA 91, 11591-11595.

Guérin, F., Le Cam, B., 2004. Breakdown of the scab resistance gene Vf in apple leads to a founder effect in populations of the fungal pathogen Venturia inequalis. Phytopathology 94, 364-369.

Hardy, O.J., Charbonnel, N., Fréville, H., Heuertz, M., 2003. Microsatellite allele sizes: a simple test to assess their significance on genetic differentiation. Genetics 163, 14671482.

Hovmøller, M.S., Justesen, A.F., Brown, J.K.M., 2002. Clonality and long-distance migration of Puccinia striiformis f. sp. tritici in north-west Europe. Plant Pathol. 51, 24-32. Jarne, P., Lagoda, P.J.L., 1996. Microsatellites, from molecules to populations and back. Trends Ecol. Evol. 11, 424-429.

Karaoglu, H., Lee, C.M.Y., Meyer, W., 2005. Survey of simple sequence repeats in 6 completed fungal genomes. Mol. Biol. Evol. 22, 639-649

7 Kaye, C., Milazzo, J., Rozenfeld, S., Lebrun, M., Tharreau, D., 2003. The development of 8 simple sequence repeat markers for Magnaporthe grisea and their integration into an 9 established genetic linkage map. Fung. Genet. Biol. 40, 207-214.

0 Kijas, J.M.H., Fowler, J.C.S., Garbett, C.A., Thomas, M.R., 1994. Enrichment of 1 microsatellites from the Citrus genome using biotinylated oligonucleotide sequences 2 bound to streptavidin-coated magnetic particles. Biotechniques 16, 656- 660.

23 Kiss, L., 1998. Natural occurrence of Ampelomyces intracellular mycoparasites in mycelia of 24 powdery mildew fungi. New Phytol. 140, 709-714. 
1 Le Guen, V., Rodier-Goud, M. Troispoux, V. Xiong, T.C., Brottier, P., Billot, C., Seguin, M., 2004. Characterization of polymorphic microsatellite markers for Microcyclus ulei, causal agent of South American leaf blight of rubber trees. Mol. Ecol. Notes 4, $122-$ 124.

Lim, S., Notley-McRobb, L., Lim, M., Carter, D.A., 2004. A comparison of the nature and abundance of microsatellites in 14 fungal genomes. Fung. Genet. Biol. 41, 1025-1036.

Lopez-Villavicencio, M., Enjalbert, J., Hood, M.E., Shykoff, J.A., Raquin, C., Giraud, T., 2005. The anther smut disease on Gypsophila repens: a case of parasite sub-optimal performance following a recent host shift? J. Evol. Biol. 18, 1293-1303.

Luikart, G., England, P.R., Tallmon, D., Jordan, S., Taberlet, P., 2003. The power and promise of population genomics: from genotyping to genome typing. Nature Rev. Genet. 4, 981-994.

Mackenzie, J.S., Chua, K.B., Daniels, P.W., Eaton, B.T., Field, H.E., Hall, R.A., Halpin, K., Johansen, C.A., Kirkland, P.D., Lam, S.K., McMinn, P., Nisbet, D.J., Paru, R., Pyke, A.T., Ritchie, S.A., Siba, P., Smith, D.W., Smith, G.A., van den Hurk, A.F., Wang, L.F., Williams, D.T., 2001. Emerging viral diseases of Southeast Asia and the western Pacific. Emerg. Infect. Dis. 7, 497-504.

Michalakis, Y., Excoffier, L., 1996. A generic estimation of population subdivision using distances between alleles with special interest to microsatellite loci. Genetics 142, 1061-1064.

Milgroom, M.G., Liparis, S., Wang, K.R., 1992. Comparison of genetic diversity in the chestnut blight fungus Cryphonectria (Endothia) parasitica, from China and the United States. Mycol. Res. 96, 1114-1120.

Morgante, M., Hanafey, M., Powell, W., 2002. Microsatellites are preferentially associated with non repetitive DNA in plant genomes. Nature Genet. 30, 194-200. 
1 Paetkau, D., Slade, R., Burden, M., Estoup, A., 2004. Genetic assignment methods for the

2

3

4

5

6 direct, real-time estimation of migration rate: a simulation-based exploration of accuracy and power. Mol. Ecol. Notes 13, 55-65.

Paraskevis, D., Lemey, P., Salemi, M., Suchard, M., Van de Peer, Y., Vandamme, A. M., 2003. Analysis of the evolutionary relationships of HIV-1 and SIVcpz sequences using Bayesian inference: Implications for the origin of HIV-1. Mol. Biol. Evol. 20, 1986-1996.

Rivas, G., Zapater, M., Abadie, C., Carlier, J., 2004. Founder effects and stochastic dispersal at the continental scale of the fungal pathogen of bananas Mycosphaerella fijiensis. Mol. Ecol. 13, 471-482.

Rosenthal, A., Coutelle, O., Craxton, M., 1993. Large-scale production of DNA sequencing templates by microtitre format PCR. Nuc. Acids Res. 21, 173-174.

Rossetto, M., 2001. Sourcing of SSR markers from related plant species. In: Henry, R.J. (Ed.), Plant Genotyping : the DNA fingerprinting of plants. CABI Publishers, New York, pp. 211-224.

Shinde, D., Lai, Y.L., Sun, F.Z., Arnheim, N., 2003. Taq DNA polymerase slippage mutation rates measured by PCR and quasi-likelihood analysis: (CA/GT)(n) and (A/T)(n) microsatellites. Nuc. Acids Res. 31, 974-980.

Squirrell, J., Hollingsworth, P.M., Woodhead, M., Russell, J., Lowe, A.J., Gibby, M., Powell, W., 2003. How much effort is required to isolate nuclear microsatellites from plants? Mol. Ecol. 12, 1339-1348.

Stephan, W., Langley, C.H., 1998. DNA polymorphism in Lycopersicon and crossing-over per physical length. Genetics 150, 1585-1593. 
1 Tenzer, I., degli Ivanissevich, S., Morgante, M. Gessler, C., 1999. Identification of

2

3

4 microsatellite markers and their application to population genetics of Venturia inaequalis. Phytopathology 89, 748-753.

Thuillet, A.C., Bru, D., David, J., Roumet, P., Santomi, S., Sourdille, P., Bataillon, T., 2002. Direct estimation of mutation rate for 10 microsatellite loci in durum wheat, Triticum turgidum (L.) Thell. ssp durum desf. Mol. Biol. Evol. 19, 122-125.

Tobler, K., Ackermann, M., Griot, C., 2003. SARS-agent and lessons to be learned from pathogenic coronaviruses of animals. Schweiz Arch. Tierh 145, 316-322.

Tóth, G., Gáspári, Z., Jurka, J., 2000. Microsatellites in Different Eukaryotic Genomes: Survey and Analysis. Genome Res. 10, 967 - 981.

Tyler, B.M., 2001. Genetics and genomics of the oomycete-host interface. Trends Genet. 17, 611-614.

Vigouroux, Y., Jaqueth, J.S., Matsuoka, Y., Smith, O.S., Beavis, W.F., Smith, J.S.C., Doebley, J., 2002. Rate and pattern of mutation at microsatellite loci in maize. Mol. Biol. Evol. 19, 1251-1260.

Wierdl, M., Dominska, M., Petes, T.D., 1997. Microsatellite Instability in Yeast: Dependence on the Length of the Microsatellite. Genetics 146, 769-779.

Zane, L., Bargelloni, L., Patarnello, T., 2002. Strategies for microsatellite isolation: a review. Mol. Ecol. 11, 1-16. 
3 Figure legends

4

5

6

7 Figure 1. Number of primer notes published in Molecular Ecology Notes between March

82001 and June 2005 (black bars) on fungi, angiosperms, fish, birds, mammals and insects. For

9 fungi, microsatellite isolation reports found in other journals are represented in grey.

11 Figure 2. Change in the average percentage of useful sequences along the different steps of

12 microsatellite isolation for 17 fungal microsatellite-enriched libraries. Percentages are given

13 for each step relative to the initial number of inserts correctly sequenced. Maximum and

14 minimum values are given by the vertical lines and dashed lines indicate limits of the first and

15 the third quartiles. See Appendix 1 for details on the libraries.

16

17 Figure 3. Boxplots of the number of repeats (A), and of the number of alleles (B) for fungi,

18 angiosperms, fishes, birds, mammals and insects. Statistics are represented on the means per

19 species for all primer notes published in Molecular Ecology Notes between March 2001 and

20 June 2006 (and published in all journals for fungi). Boxes indicate quartiles, dark squares

21 means and vertical traits minimal and maximal values. Different letters indicate significantly

22 different groups of means in a SNK pairwise comparison test $(\mathrm{P}<0.05)$. 


\section{ACCEPTED MANUSCRIPT}

1 Figure 4. Mean number of alleles per species plotted against mean number of repeats (of the

2 longest pure tandem repeat) for all available data on fungal dinucleotide microsatellites. The

3 regression line is drawn $(\mathrm{r}=0.28, \mathrm{P}=0.06)$.

4 
Table 1. Fungal species for which the authors built microsatellite-enriched libraries, with their characteristics.

\begin{tabular}{|c|c|c|c|c|}
\hline Species & Order & $\begin{array}{l}\text { Method of } \\
\text { enrichment }\end{array}$ & Motif for enriched libraries & $\begin{array}{l}\text { Number of } \\
\text { screened } \\
\text { individuals }\end{array}$ \\
\hline Cryphonectria parasitica & Ascomycota & membrane & $(\mathrm{AC})_{15}(\mathrm{AG})_{15}(\mathrm{AAG})_{10}$ & 113 \\
\hline $\begin{array}{l}\text { Erysiphe alphitoides } \\
\text { (2 libraries) }\end{array}$ & Ascomycota & $\begin{array}{l}\text { Membrane } \\
\text { beads }\end{array}$ & $\begin{array}{ll}(\mathrm{AC})_{15} & (\mathrm{AG})_{15}(\mathrm{AAG})_{10} \\
(\mathrm{AC})_{15} & (\mathrm{AG})_{15}\end{array}$ & 8 \\
\hline $\begin{array}{l}\text { Erysiphe necator } \\
\text { (2 libraries) }\end{array}$ & Ascomycota & beads & $(\mathrm{TC})_{10}(\mathrm{TG})_{10}$ & 15 \\
\hline Fusarium culmorum & Ascomycota & beads & $(\mathrm{AC})_{10}(\mathrm{AAG})_{10}$ & 20 \\
\hline Fusarium poe & Ascomycota & beads & $(\mathrm{AC})_{10}$ & 20 \\
\hline Magnaporthe grisea & Ascomycota & beads & $(\mathrm{TC})_{15}(\mathrm{AC})_{15}$ & 6 \\
\hline $\begin{array}{l}\text { Melampsora larici- } \\
\text { populina } \\
\text { (5 libraries) }\end{array}$ & Basidiomycota & $\begin{array}{l}\text { membrane } \\
\text { beads } \\
\text { beads }\end{array}$ & $\begin{array}{l}(\mathrm{AC})_{15}(\mathrm{AG})_{15}(\mathrm{AAG})_{10} \\
(\mathrm{AC})_{15}(\mathrm{AG})_{15} \\
(\mathrm{TC})_{10}(\mathrm{TG})_{10}\end{array}$ & 30 \\
\hline $\begin{array}{l}\text { Microbotryum violaceum } \\
\text { (3 libraries) }\end{array}$ & Basidiomycota & beads & $(\mathrm{AC})_{10}(\mathrm{AAG})_{10}$ & 30 \\
\hline Mycosphaerella musicola & Ascomycota & & $(\mathrm{TC})_{15}(\mathrm{AC})_{15}$ & 15 \\
\hline Mycosphaerella fijiensis & Ascomycota & beads & $(\mathrm{TC})_{15}(\mathrm{AC})_{15}$ & 15 \\
\hline Mycosphaerella eumusae & Ascomycota & beads & $(\mathrm{TC})_{15}(\mathrm{AC})_{15}$ & 15 \\
\hline Mycrocyclus ulei & Ascomycota & beads & (TC) $15(\mathrm{AC})_{15}$ & 16 \\
\hline $\begin{array}{l}\text { Penicillium roqueforti } \\
\text { (4 libraries) }\end{array}$ & Ascomycota & beads & $(\mathrm{AC})_{10}(\mathrm{AAG})_{10}(\mathrm{CAC})_{10}(\mathrm{GGA})_{10}$ & 5 \\
\hline Penicillium camembertii & Ascomycota & beads & $(\mathrm{AC})_{10}(\mathrm{AAG})_{10}$ & 5 \\
\hline Plasmopara viticola & Oomycota & beads & $(\mathrm{TC})_{10}(\mathrm{TG})_{10}(\mathrm{GAA})_{10}(\mathrm{TAA})_{10}$ & 100 \\
\hline $\begin{array}{l}\text { Puccinia striiformis } f s p \\
\text { tritici }\end{array}$ & Basidiomycota & beads & $(\mathrm{AC})_{10}(\mathrm{AG})_{10}(\mathrm{AAC})_{10}(\mathrm{AAG})_{10}$ & 96 \\
\hline Puccinia triticina & Basidiomycota & beads & $(\mathrm{AC})_{10}(\mathrm{AG})_{10}(\mathrm{AAC})_{10}(\mathrm{AAG})_{10}$ & 15 \\
\hline
\end{tabular}


Table 2. Results of the GENMOD analysis testing for an effect of repeat number, imperfection and motif of the loci, species and sample size on the allele number of microsatellites $\left(\mathrm{R}^{2}=0.49\right)$.

\begin{tabular}{lcrr}
\hline Source & D. F. & Chi Square & \multicolumn{1}{c}{ P } \\
\hline Number of repeats & 1 & 25.34 & $<0.0001$ \\
Imperfection & 1 & 1.59 & 0.2076 \\
motif & 1 & 0.48 & 0.4888 \\
Species & 40 & 223.39 & $<0.0001$ \\
Sample size & 1 & 0.49 & 0.4828 \\
\hline
\end{tabular}


Number of published papers

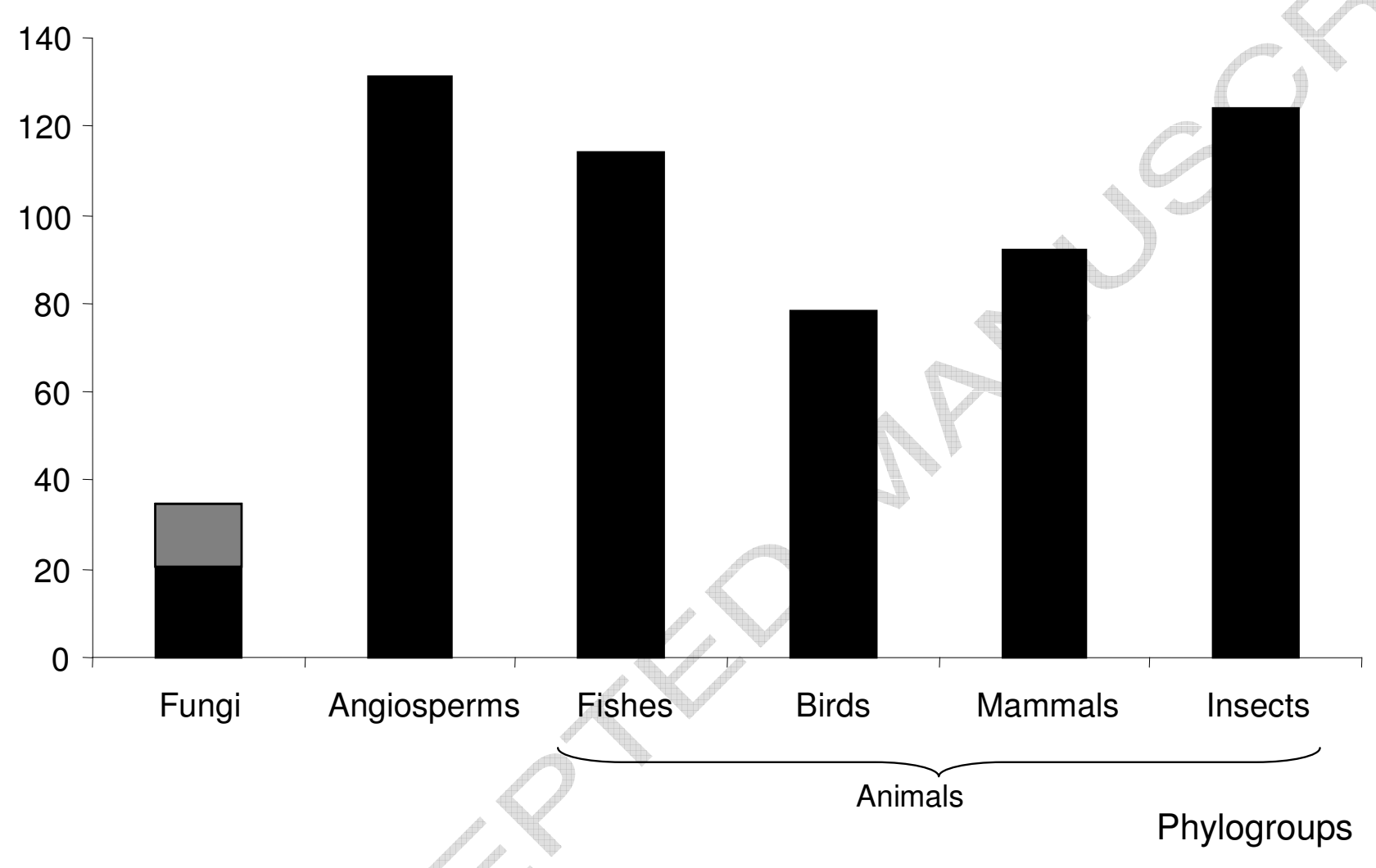

Dutech et al. Figure 1 


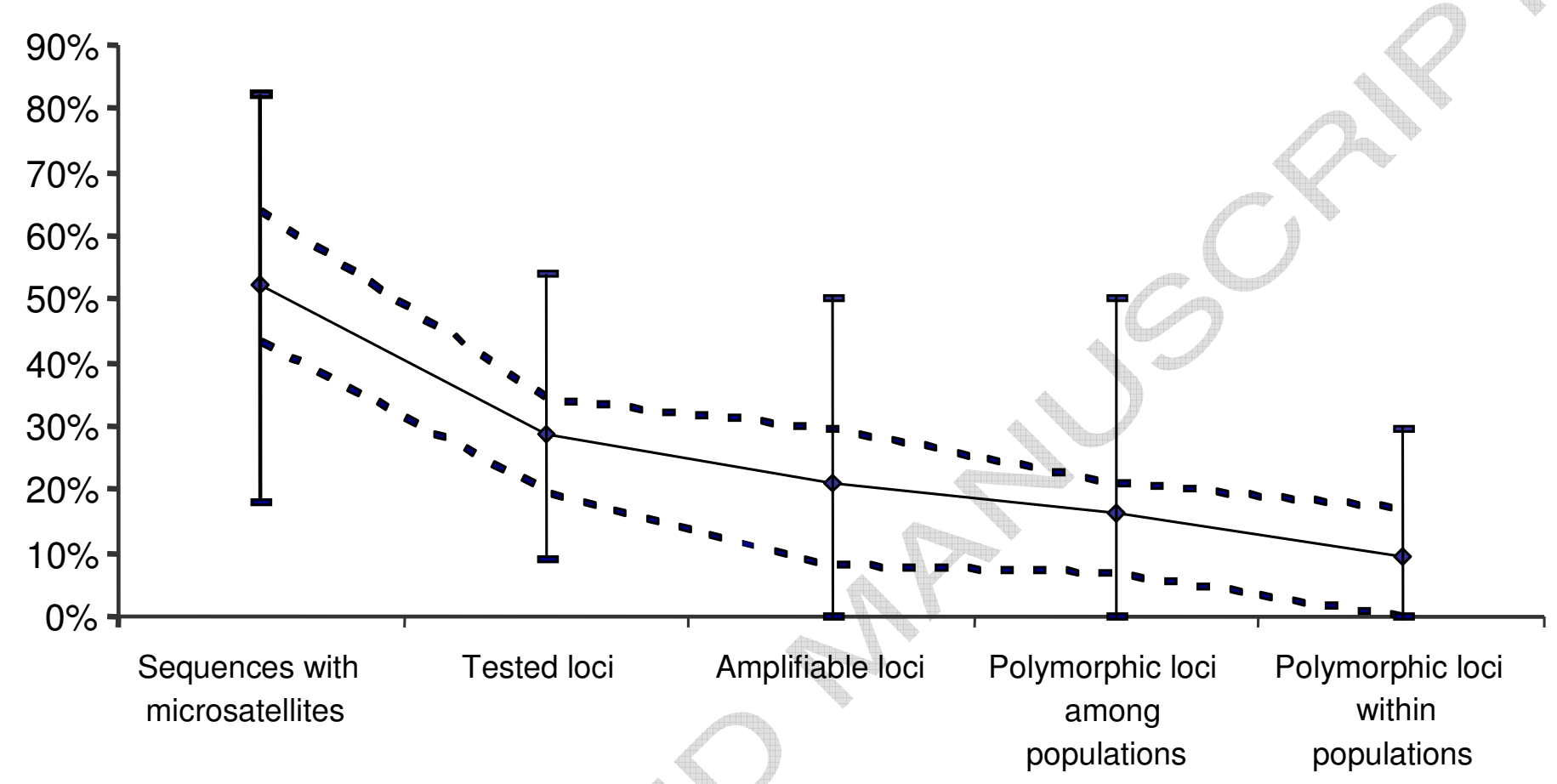

Dutech et al. Figure 2 
Number of repeats

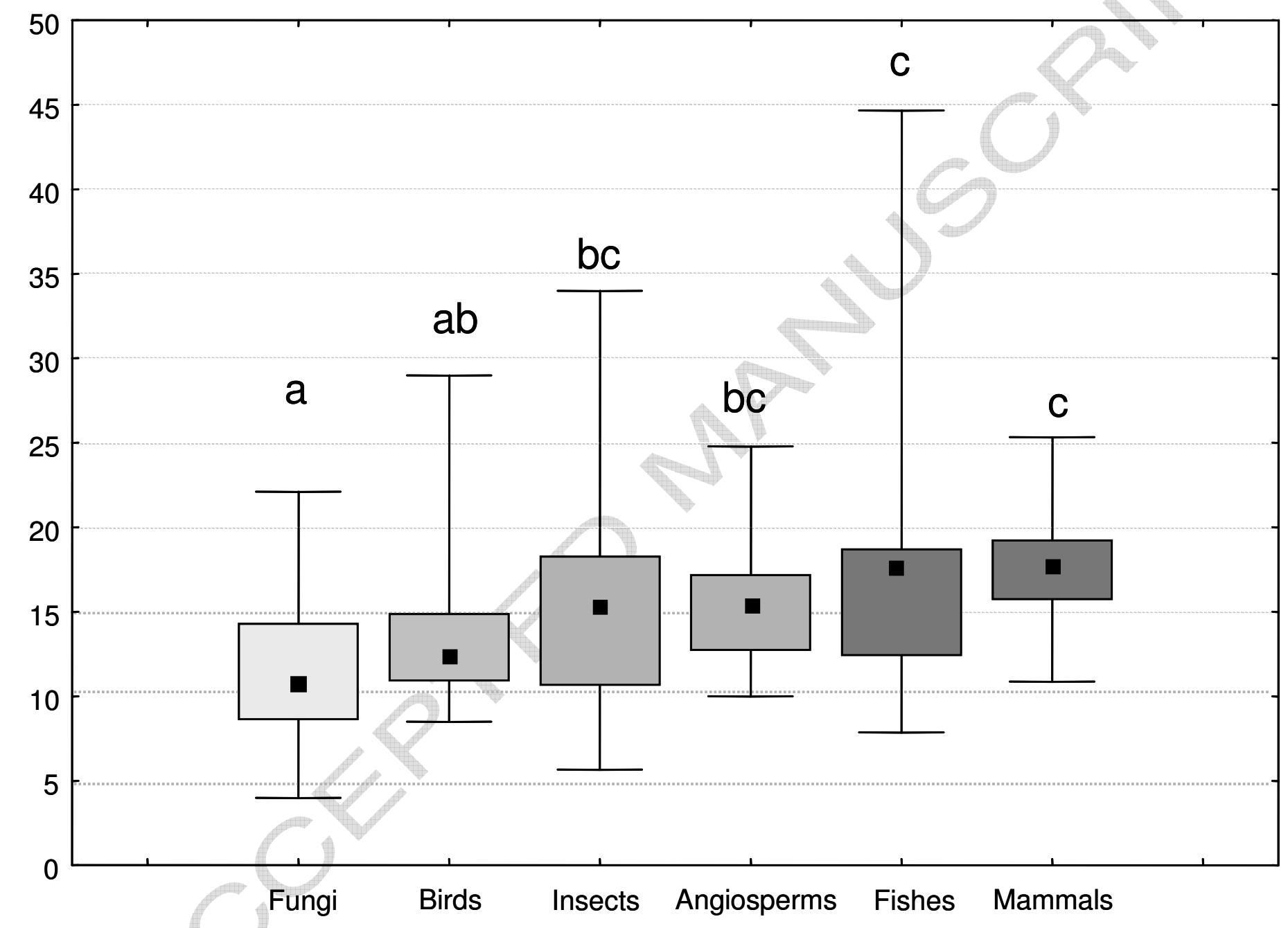

Figure 3A Dutech et al. 
Number of alleles

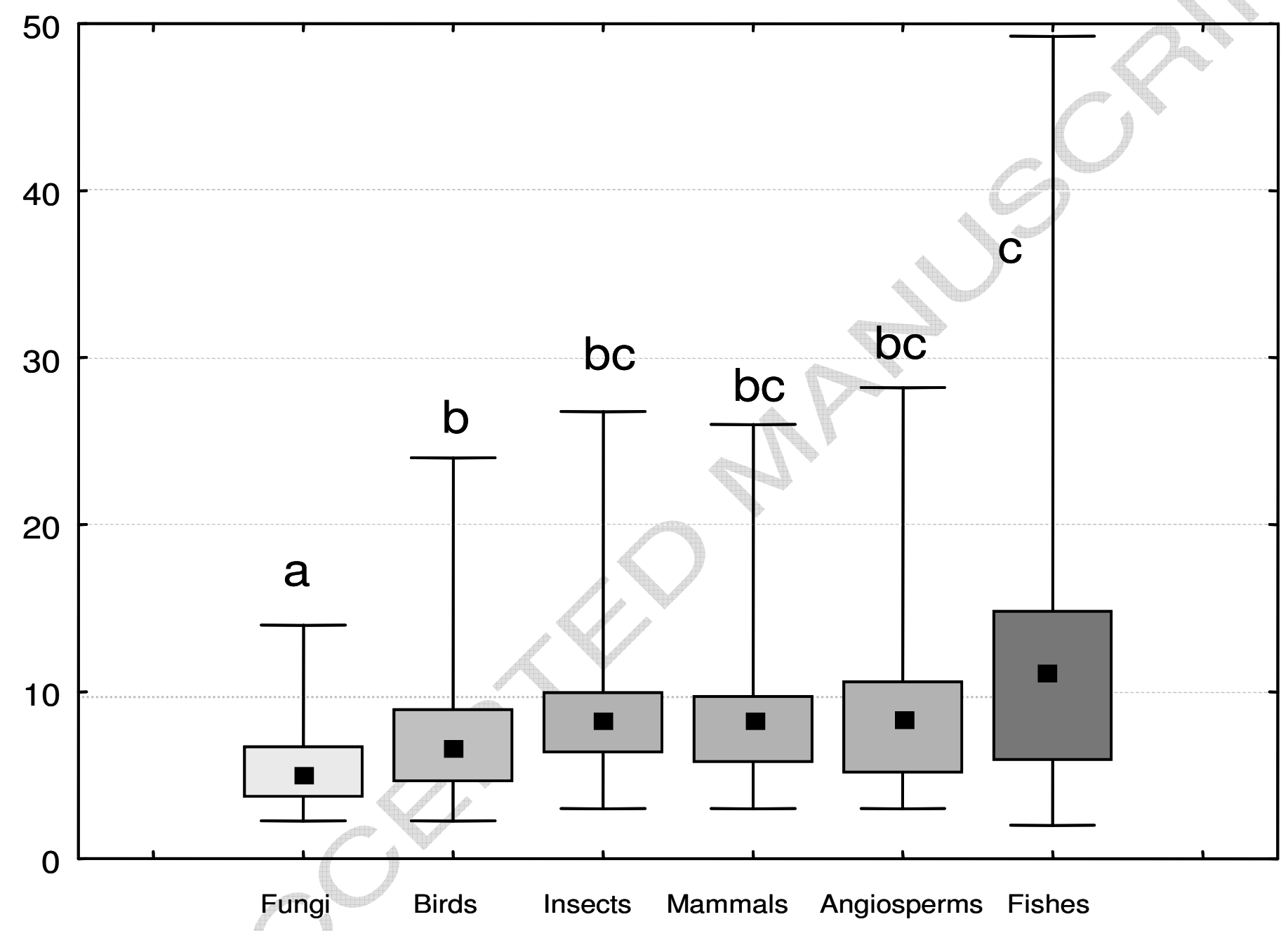

Figure 3B Dutech et al. 


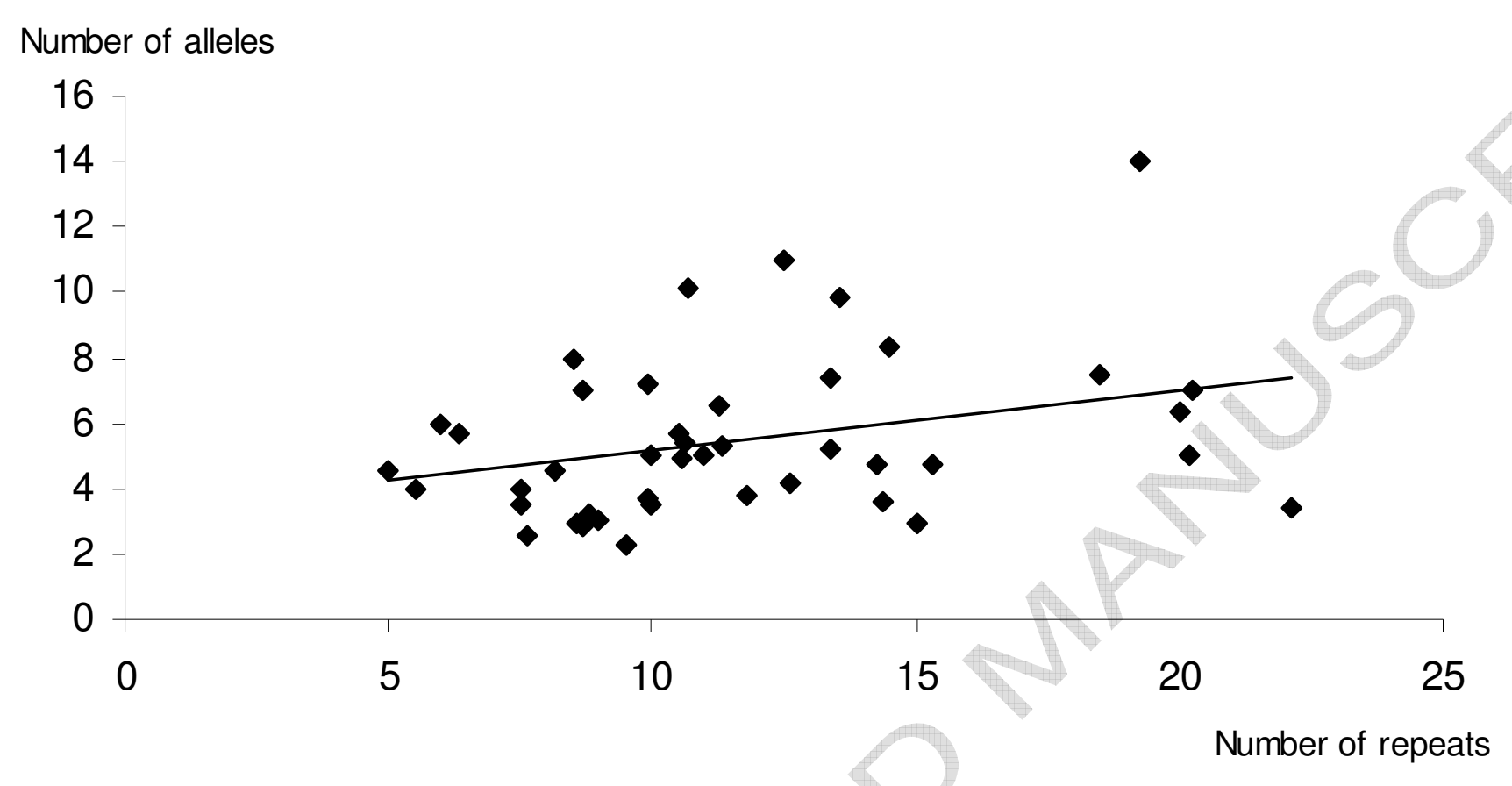

Dutech et al. Figure 4 
Appendix 1. Proportion of useful loci along the different steps of microsatellite development in 17 fungal species. The percentages are relative to the initial number of sequenced clones.

\begin{tabular}{|c|c|c|c|c|c|c|}
\hline Species & $\begin{array}{l}\text { Number of } \\
\text { sequenced } \\
\text { clones }\end{array}$ & $\begin{array}{c}\text { Percentage of } \\
\text { unique } \\
\text { sequences with a } \\
\text { microsatellite }\end{array}$ & $\begin{array}{l}\text { Percentage of } \\
\text { sequences } \\
\text { suitable for } \\
\text { primer design }\end{array}$ & $\begin{array}{c}\text { Percentage of } \\
\text { sequences } \\
\text { yielding correct } \\
\text { amplification }\end{array}$ & $\begin{array}{l}\text { Percentage of } \\
\text { sequences } \\
\text { yielding } \\
\text { polymorphic } \\
\text { loci at the } \\
\text { largest scale }\end{array}$ & $\begin{array}{l}\text { Percentage of } \\
\text { sequences yielding } \\
\text { intra-population } \\
\text { polymorphic loci }\end{array}$ \\
\hline Cryphonectria parasitica & 58 & 44.8 & 29.3 & 27.6 & 17.2 & 17.2 \\
\hline Fusarium culmorum & 33 & 57.6 & 27.3 & 27.3 & 24.2 & 23.7 \\
\hline Fusarium poae & 137 & 63.5 & 14.6 & 1.5 & 1.5 & 1.5 \\
\hline Erysiphe alphitoides & 110 & 19.1 & 9.1 & 0.0 & 0.0 & 0.0 \\
\hline Erysiphe necator & 96 & 79.2 & 18.8 & 8.3 & 3.1 & 2.1 \\
\hline Magnaporthe grisea & 96 & 46.9 & 20.8 & 10.4 & 10.4 & 10.4 \\
\hline Melampsora larici-populina & 208 & 17.8 & 17.8 & 7.2 & 6.7 & 6.3 \\
\hline Microbotryum violaceum & 143 & 42.0 & 30.8 & 30.8 & 30.8 & 13.0 \\
\hline Microcyclus ulei & 52 & 46.2 & 26.9 & 25.0 & 21.2 & 21.2 \\
\hline Mycosphaerella eumusae & 58 & 63.8 & 32.8 & 19.0 & 15.5 & 15.5 \\
\hline Mycosphaerella fijiensis & 111 & 46.8 & 43.2 & 29.7 & 29.7 & 29.7 \\
\hline Mycosphaerella musicola & 64 & 53.1 & 34.4 & 18.8 & 18.8 & 18.8 \\
\hline Penicillium camembertii & 24 & 66.7 & 54.2 & 50.0 & 50.0 & 0.0 \\
\hline Penicillium roqueforti & 23 & 43.5 & 43.5 & 39.1 & 17.4 & 0.0 \\
\hline Plasmopara viticola & 186 & 37.1 & 19.9 & 4.8 & 3.8 & 3.8 \\
\hline Puccinia striiformis fsp tritici & 79 & 75.9 & 35.4 & 30.4 & 15.2 & 0.0 \\
\hline Puccinia triticina & 130 & 82.3 & 27.7 & 23.8 & 9.2 & 0.0 \\
\hline Mean & & $52.1 \pm 4.7$ & $28.6 \pm 3.9$ & $20.8 \pm 3.5$ & $16.2 \pm 3.2$ & $9.6 \pm 2.5$ \\
\hline
\end{tabular}


Appendix 2. Isolation and characterization of microsatellite loci in fungal species

\section{OUR DATA}

\begin{tabular}{|c|c|c|c|c|c|c|c|c|c|}
\hline Species & $\begin{array}{l}\text { Method of library } \\
\text { enrichment }\end{array}$ & $\begin{array}{l}\mathrm{Nb} \text { of tested } \\
\text { primers }\end{array}$ & $\begin{array}{l}\text { Percentage of } \\
\text { scorable loci }\end{array}$ & $\begin{array}{c}\text { Percentage of } \\
\text { polymorphic } \\
\text { loci }\end{array}$ & $\begin{array}{l}\mathrm{Nb} \text { of loci } \\
\text { used for } \\
\text { analyses }^{(1)}\end{array}$ & $\begin{array}{l}\mathrm{Nb} \text { of } \\
\text { repeats }\end{array}$ & $\begin{array}{c}\mathrm{Nb} \text { of } \\
\text { alleles }^{(2)}\end{array}$ & $\begin{array}{c}\mathrm{Nb} \text { of strains } \\
\text { tested }\end{array}$ & References \\
\hline Cryphonectria parasitica & Membrane and $\mathrm{EST}^{(3)}$ & 17 & 94 & 59 & 8 & 13.3 & 4.9 & 113 & Breuillin et al. (2006) \\
\hline Erysiphe necator & Beads & 18 & 44 & 11 & DA & DA & DA & DA & Unpublished \\
\hline Fusarium culmorum & Beads & 9 & 100 & 89 & 7 & 13.0 & 6.1 & 20 & Giraud et al. (2002a) \\
\hline Fusarium poae & Beads & 20 & 10 & 10 & DA & DA & DA & DA & Unpublished \\
\hline Magnaporthe grisea & Beads and $\mathrm{EST}^{(3)}$ & 19 & 50 & 30 & 24 & 16.7 & 2.9 & 6 & $\begin{array}{l}\text { Kaye et al. (2003) and } \\
\text { unpublished }\end{array}$ \\
\hline Melampsora larici-populina & Beads and membrane & 37 & 41 & 35 & 12 & 9.7 & 4.9 & 30 & Barrès et al. (2005) \\
\hline Microbotryum violaceum & Beads & 44 & 100 & 100 & 44 & 11.4 & 5.4 & 30 & Giraud et al. (2002b) \\
\hline Microcyclus ulei & Beads & 14 & 93 & 93 & 11 & 15.0 & 2.9 & 16 & $\begin{array}{l}\text { Le Guen et al. (2004) and } \\
\text { unpublished }\end{array}$ \\
\hline Mycosphaerella eumusae & Beads & 19 & 58 & 47 & 9 & 8.6 & 2.9 & 15 & Unpublished \\
\hline Mycosphaerella fijiensis & Beads & 48 & 69 & 69 & 33 & 10.2 & 4.6 & 15 & Unpublished \\
\hline Mycosphaerella musicola & Beads & 19 & 63 & 63 & 12 & 10.2 & 4.1 & 15 & Unpublished \\
\hline Penicillium camembertii & Beads & 13 & 100 & 92 & 11 & 12.2 & 2.6 & 5 & Unpublished \\
\hline Penicillium roqueforti & Beads & 19 & 84 & 37 & 4 & 11.8 & 3.5 & 5 & Unpublished \\
\hline Plasmopara viticola & Beads & 15 & 40 & 40 & 6 & 8.2 & 4.5 & 100 & Delmotte et al. (2006) \\
\hline $\begin{array}{l}\text { Puccinia striiformis fsp } \\
\text { tritici }\end{array}$ & Beads & & 86 & 43 & 11 & 7.3 & 2.5 & 96 & Enjalbert et al. (2002) \\
\hline Puccinia triticina & Beads & 36 & 86 & 33 & 12 & 8.1 & 3.2 & 15 & Duan et al. (2003) \\
\hline Mean & & $23.4 \pm 3.0$ & $69.9 \pm 7.0$ & $53.2 \pm 7.4$ & $14.6 \pm 2.9$ & $11.1 \pm 0.7$ & $4.1 \pm 0.3^{(4)}$ & $44.4 \pm 12.1$ & \\
\hline
\end{tabular}




\section{LITERATURE DATA}

\begin{tabular}{|c|c|c|c|c|c|c|c|c|c|}
\hline Species & $\begin{array}{l}\text { Method of library } \\
\text { enrichment }\end{array}$ & $\begin{array}{l}\mathrm{Nb} \text { of tested } \\
\text { primers }\end{array}$ & $\begin{array}{l}\text { Percentage of } \\
\text { scorable loci }\end{array}$ & $\begin{array}{c}\text { Percentage of } \\
\text { polymorphic } \\
\text { loci }\end{array}$ & $\begin{array}{c}\mathrm{Nb} \text { of } \\
\text { published } \\
\text { loci }{ }^{(1)}\end{array}$ & $\begin{array}{c}\mathrm{Nb} \text { of } \\
\text { repeats }\end{array}$ & $\begin{array}{c}\mathrm{Nb} \text { of } \\
\text { alleles }^{(2)}\end{array}$ & $\begin{array}{l}\mathrm{Nb} \text { of strains } \\
\text { tested }\end{array}$ & References \\
\hline Alternaria brassicicola & Beads & 21 & 81 & 57 & 12 & 8.7 & 2.9 & 46 & Avenot et al. (2005) \\
\hline Armillaria ostoyae & Membrane & 12 & 100 & 100 & 12 & 9.9 & 7.2 & 23 & Langrell et al. (2001) \\
\hline Ascochyta rabiei & Non enriched & 37 & 70 & 54 & 20 & 12.6 & 4.2 & 22 & Geistlinger et al. (2000) \\
\hline Aspergillus flavus & GenBank $^{(5)}$ & NA & NA & NA & 6 & 13.4 & 7.4 & 20 & Tran-Dinh \& Carter (2000) \\
\hline Aspergillus parasiticus & GenBank & NA & NA & NA & 6 & 13.4 & 5.2 & 15 & Tran-Dinh \& Carter (2000) \\
\hline Aspergillus fumigatus & Non enriched & 8 & 100 & 50 & 4 & 19.3 & 14.0 & 100 & Bart-Delabesse et al. (1998) \\
\hline Beauveria brongniartii & Beads & 11 & 91 & 91 & 10 & 11.8 & 3.8 & 96 & Enkerli et al. (2001) \\
\hline Beauveria bassiana & Beads & NR & NR & NR & 8 & 20.0 & 6.3 & 24 & Rehner \& Buckley (2003) \\
\hline Botryosphaeria parva & $\operatorname{ISSR}^{(6)}$ & 20 & NR & 35 & 5 & 9.0 & 3.0 & 82 & Slippers et al. (2004) \\
\hline Botryosphaeria rhodina & ISSR & 19 & 68 & 42 & 5 & 5.0 & 4.0 & 9 & Burgess et al. (2003) \\
\hline Coccidioides immitis & Non enriched & 9 & 100 & 100 & 9 & 13.6 & 9.9 & 25 & Fisher et al. (1999) \\
\hline Cryphonectria eucalypti & FIASCO $^{(7)}$ & NR & NR & NR & 8 & 20.3 & 7.0 & 20 & Nakabonge et al. (2005) \\
\hline Cylindrocladium parasiticum & ISSR & 25 & NR & 48 & 8 & 7.5 & 3.5 & 17 & Wright et al. (2006) \\
\hline Dothistroma pini & Anchored and EST & 9 & & 33 & 4 & 6.7 & 2.7 & 12 & Ganley \& Bradshaw (2001) \\
\hline Fusarium oxysporum & ISSR & NR & & NR & 9 & 12.5 & 11 & 64 & Bogale et al. (2005) \\
\hline Heterobasidion annosum & Beads & NR & NR & NR & 5 & 11.3 & 6.5 & 19 & Johannesson \& Stenlid (2004) \\
\hline Laccaria bicolor & Beads & 150 & 26 & 5 & 7 & 8.7 & 7.0 & 12 & Jany et al. (2006) \\
\hline Leptosphaeria maculans & $\begin{array}{c}\text { Non enriched and } \\
\text { EST }\end{array}$ & & 94 & 19 & 6 & 9.5 & 2.3 & 14 & Hayden et al. (2004) \\
\hline Lobaria pulmonaria & Beads & 21 & 57 & 52 & 11 & 14.5 & 8.3 & 30 & Walser et al. (2003) \\
\hline Melampsora lini & FIASCO & 41 & 83 & 27 & 10 & 7.5 & 4 & 102 & Barett \& Brubaker (2006) \\
\hline Metarhizium anisopliae & Beads & 14 & 100 & 100 & 8 & 10.6 & 5.4 & 34 & Enkerli et al. (2005) \\
\hline Mycosphaerella fijiensis & Beads & 19 & 58 & 58 & 10 & 20.2 & 5.0 & 29 & Neu et al. (1999) \\
\hline Mycosphaerella musicola & Beads & 48 & NR & 54 & 24 & 22.1 & 3.4 & 24 & Molina et al. (2001) \\
\hline Mycosphaerella populorum & EST & 10 & NR & 50 & 3 & 11 & 5 & 77 & Feau et al. (2006) \\
\hline Paecilomyces fumosoroseus & Beads & 9 & 100 & 89 & 8 & 14.4 & 3.6 & 26 & Dalleau-Clouet et al. (2005) \\
\hline
\end{tabular}




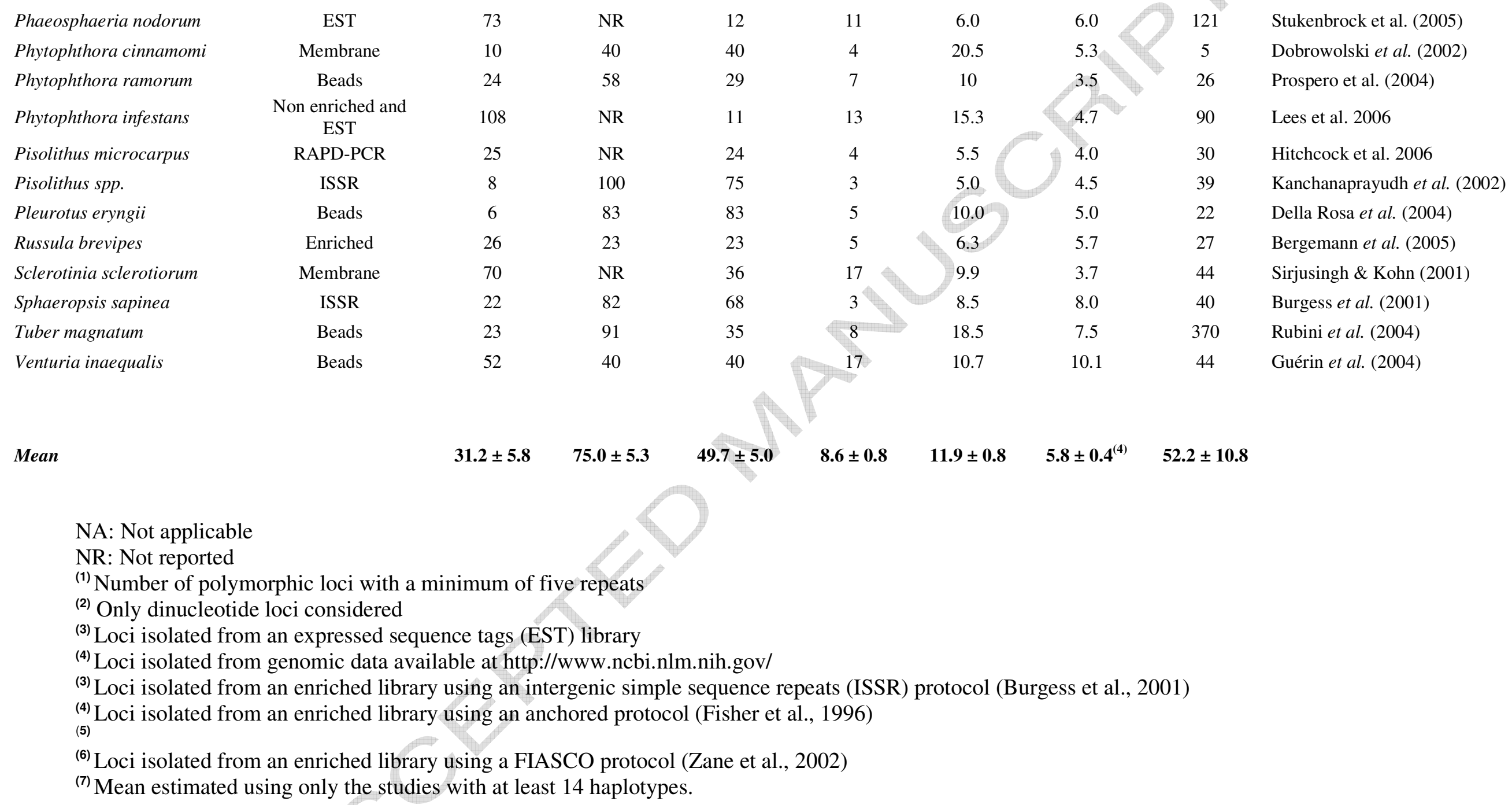

$\begin{array}{cc}\text { EST } & 73 \\ \text { Membrane } & 10 \\ \text { Beads } & 24 \\ \text { Non enriched and } & 108 \\ \text { EST } & 25 \\ \text { RAPD-PCR } & 8 \\ \text { ISSR } & 6 \\ \text { Beads } & 26 \\ \text { Enriched } & 70 \\ \text { Membrane } & 22 \\ \text { ISSR } & 23 \\ \text { Beads } & 52 \\ \text { Beads } & \end{array}$

NR
40
58
NR
NR
100
83
23
NR
82
91
40

12
40
29
11
24
75
83
23
36
68
35
40

11
4
7
13

$\begin{array}{ccc}6.0 & 6.0 & 121 \\ 20.5 & 5.3 & 5 \\ 10 & 3.5 & 26 \\ 15.3 & 4.7\end{array}$

15.3

Stukenbrock et al. (2005)

Dobrowolski et al. (2002)

Prospero et al. (2004)

Lees et al. 2006

Hitchcock et al. 2006

Kanchanaprayudh et al. (2002)

Della Rosa et al. (2004)

Bergemann et al. (2005)

Sirjusingh \& Kohn (2001)

Burgess et al. (2001)

Rubini et al. (2004)

Guérin et al. (2004)

NA: Not applicable

NR: Not reported

(1) Number of polymorphic loci with a minimum of five repeats

(2) Only dinucleotide loci considered

(3) Loci isolated from an expressed sequence tags (EST) library

${ }^{(4)}$ Loci isolated from genomic data available at http://www.ncbi.nlm.nih.gov/

${ }^{(3)}$ Loci isolated from an enriched library using an intergenic simple sequence repeats (ISSR) protocol (Burgess et al., 2001) ${ }_{(5)}^{(4)}$ Loci isolated from an enriched library using an anchored protocol (Fisher et al., 1996)

${ }^{(6)}$ Loci isolated from an enriched library using a FIASCO protocol (Zane et al., 2002)

${ }^{(7)}$ Mean estimated using only the studies with at least 14 haplotypes. 


\section{References}

Avenot, H., Dongo, A., Bataille-Simoneau, N., Iacomi-Vasilescu, B., Hamon, B., Peltier, D., Simoneau, P., 2005. Isolation of 12 polymorphic microsatellite loci in the phytopathogenic fungus Alternaria brassicicola. Mol. Ecol. Notes 5, 948-950.

Barrès, B., Dutech, C., Andrieux, A., Caron, H., Pinon, J., Frey, P., 2006. Isolation and characterization of 15 microsatellite loci in the poplar rust fungus, Melampsora larici-populina, and cross-amplification in related species. Mol. Ecol. Notes 6, 60-64.

Barrett, L.G., Brubaker, C.L., 2006. Isolation and characterization of microsatellite loci from the rust pathogen, Melampsora lini. Mol. Ecol. Notes 6, 930-932.

Bart-Delabesse, E., Humbert, J.F., Delabesse, E., Bretagne, S., 1998. Microsatellite markers for typing Aspergillus fumigatus isolates. J. Clin. Microbiol. 36, 2413-2418.

Bergemann, S.E., Miller, S.L., Garbelotto, M., 2005. Microsatellite loci from Russula brevipes, a common ectomycorrhizal associate of several tree species in North America. Mol. Ecol. Notes 5, 472-474.

Bogale, M., Wingfield, B.D., Wingfield, M.J., Steenkamp, E.T., 2005. Simple sequence repeat markers for species in the Fusarium oxysporum complex. Mol. Ecol. Notes 5, 622-624.

Breuillin, F., Dutech, C., Robin, C., 2006. Genetic diversity of the chestnut blight fungus Cryphonectria parasitica within four French populations assessed by microsatellite loci. Mycol. Res. 110, 288-296.

Burgess, T., Wingfield, M.J., Wingfield, B.D., 2003. Development and characterization of microsatellite loci for the tropical tree pathogen Botryosphaeria rhodina. Mol. Ecol. Notes 3, 91-94.

Burgess, T., Wingfield, M.J., Wingfield, B.W., 2001. Simple sequence repeat markers distinguish among morphotypes of Sphaeropsis sapinea. Appl. Environ. Microbiol. 67, 354-362.

Dalleau-Clouet, C., Gauthier, N., Risterucci, A.M., Bon, M.C., Fargues, J., 2005. Isolation and characterization of microsatellite loci from the entomopathogenic hyphomycete, Paecilomyces fumosoroseus. Mol. Ecol. Notes 5, 496-498.

Della Rosa, V., Cappuccio, I., Fanelli, C., Urbanelli, S., 2004. Isolation and characterization of microsatellite markers in two basidiomycete species: Pleurotus eryngii and P. ferulae. Mol. Ecol. Notes 4, 271-273.

Delmotte, F., Chen, W., Richard-Cervera, S., Greif, C., Papura, D., Giresse, X., Mondor-Genson, G., Corio-Coste, M., 2006. Microsatellite DNA markers for Plasmopara viticola, the causal agent of downy mildew of grapes. Mol. Ecol. Notes 6, 379-381.

Dobrowolski, M.P., Tommerup, I.C., Blakeman, H.D., O'Brien, P.A., 2002. Non-mendelian inheritance revealed in a genetic analysis of sexual progeny of Phytophthora cinnamomi with microsatellite markers. Fungal Genet. Biol. 35, 197-212.

Duan, X., Enjalbert, J., Vautrin, D., Solignac, M., Giraud, S., 2003. Isolation of 12 microsatellite loci, using an enrichment protocol, in the phytopathogenic fungus Puccinia triticina. Mol. Ecol. Notes 3, 65-67.

Enjalbert, J., Duan, X., Giraud, T., Vautrin, D., de Vallavielle-Pope, C., Solignac, M., 2002. Isolation of twelve microsatellite loci, using an enrichment protocol, in the phytopathogenic fungus Puccinia striiformis f.sp tritici. Mol. Ecol. Notes 2, 563-565.

Enkerli, J., Kolliker, R., Keller, S., Widmer, F., 2005. Isolation and characterization of microsatellite markers from the entomopathogenic fungus Metarhizium anisopliae. Mol. Ecol. Notes 5, 384-386. 
Enkerli, J., Widmer, F., Gessler, C., Keller, S., 2001. Strain-specific microsatellite markers in the entomopathogenic fungus Beauveria brongniartii. Mycol. Res. 105, 1079-1087.

Feau, N., Jacobi, V., Hamelin, R.C., Bernier, L., 2006. Screening of ESTs from Septoria musiva (teleomorph Mycosphaerella populorum) for detection of SSR and PCR-RFLP markers. Mol. Ecol. Notes 6, 356-358.

Fisher, M.C., White, T.J., Taylor, J.W., 1999. Primers for genotyping single nucleotide polymorphisms and microsatellites in the pathogenic fungus Coccidioides immitis. Mol. Ecol. 8, 1082-1084.

Ganley, R.J., Bradshaw, R.E., 2001. Rapid identification of polymorphic microsatellite loci in a forest pathogen, Dothistroma pini, using anchored PCR. Mycol. Res. 105, 1075-1078.

Geistlinger, J., Weising, K., Winter, P., Kahl, G., 2000. Locus-specific microsatellite markers for the fungal chickpea pathogen Didymella rabiei (anamorph) Ascochyta rabiei. Mol. Ecol. 9, 1939-1941.

Giraud, T., Fournier, E., Vautrin, D., Solignac, M., Vercken, E., Bakan, B., Brygoo, Y., 2002a. Isolation of eight polymorphic microsatellite loci, using an enrichment protocol, in the phytopathogenic fungus Fusarium culmorum. Mol. Ecol. Notes 2, 121-123.

Giraud, T., Fournier, E., Vautrin, D., Solignac, M., Shykoff, J.A., 2002b. Isolation of 44 polymorphic microsatellite loci in three host races of the phytopathogenic fungus Microbotryum violaceum. Mol. Ecol. Notes 2, 142-146.

Guerin, F., Franck, P., Loiseau, A., Devaux, M., Le Cam, B., 2004. Isolation of 21 new polymorphic microsatellite loci in the phytopathogenic fungus Venturia inaequalis. Mol. Ecol. Notes 4, 268-270.

Hayden, H.L., Wilson, L.M., Cozijnsen, A.J., Howlett, B.J., 2004. Characterization and cross-species amplification of microsatellite loci in the plant pathogenic fungus Leptosphaeria maculans. Mol. Ecol. Notes 4, 480-481.

Hitchcock, C.J., Chambers, S.M., Cairney, J.W.G., 2006. Development of polymorphic simple sequence repeat markers for Pisolithus microcarpus. Mol. Ecol. Notes 6, 443-445.

Jany, J.L., Bousquet, J., Gagne, A., Khasa, D.P., 2006. Simple sequence repeat (SSR) markers in the ectomycorrhizal fungus Laccaria bicolor for environmental monitoring of introduced strains and molecular ecology applications. Mycol. Res. 110, 51-59.

Johannesson, H., Stenlid, J., 2004. Nuclear reassortment between vegetative mycelia in natural populations of the basidiomycete Heterobasidion annosum. Fungal Genet. Biol. 41, 563-570.

Kanchanaprayudh, J., Lian, C., Zhou, Z., Hogetsu, T., Sihanonth, P., 2002. Polymorphic microsatellite markers of a Pisolithus sp from a Eucalyptus plantation Mol. Ecol. Notes 2, 263-264.

Kaye, C., Milazzo, J., Rozenfeld, S., Lebrun, M.-H., Tharreau, D., 2003. The development of simple sequence repeat markers for Magnaporthe grisea and their integration into an established genetic linkage map. Fungal Genet. Biol. 40, 207-214.

Langrell, S.R.H., Lung-Escarmant, B., Decroocq, S., 2001. Isolation and characterization of polymorphic simple sequence repeat loci in Armillaria ostoyae. Mol. Ecol. Notes 1, 305-307.

Le Guen, V., Rodier-Goud, M., Troispoux, V., Xiong, T.C., Brottier, P., Billot, C., Seguin, M., 2004. Characterization of polymorphic microsatellite markers for Microcyclus ulei, causal, agent of South American leaf blight of rubber trees. Mol. Ecol. Notes 4, 122-124.

Lees, A.K., Wattier, R., Shaw, D.S., Sullivan, L., Williams, N.A., Cooke, D.E.L., 2006. Novel microsatellite markers for the analysis of Phytophthora infestans populations. Plant Pathology 55, 311-319. 
Molina, C., Kaemmer, D., Aponte, S., Weising, K., Kahl, G., 2001. Microsatellite markers for the fungal banana pathogen Mycosphaerella musicola. Mol. Ecol. Notes 1, 137-139.

Nakabonge, G., Cortinas, M.N., Roux, J., Gryzenhout, M., Wingfield, B.D., Wingfield, M.J., 2005. Development of polymorphic microsatellite markers for the fungal tree pathogen Cryphonectria eucalypti. Mol. Ecol. Notes 5, 558-561.

Neu, C., Kaemmer, D., Kahl, G., Fischer, D., Weising, K., 1999. Polymorphic microsatellite markers for the banana pathogen Mycosphaerella fijiensis. Mol. Ecol. 8, 523-525.

Prospero, S., Black, J.A., Winton, L.M., 2004. Isolation and characterization of microsatellite markers in Phytophthora ramorum, the causal agent of sudden oak death. Mol. Ecol. Notes 4, 672-674.

Rehner, S.A., Buckley, E.P., 2003. Isolation and characterization of microsatellite loci from the entomopathogenic fungus Beauveria bassiana (Ascomycota : Hypocreales). Mol. Ecol. Notes 3, 409-411.

Rubini, A., Topini, F., Riccioni, C., Paolocci, F., Arcioni, S., 2004. Isolation and characterization of polymorphic microsatellite loci in white truffle (Tuber magnatum). Mol. Ecol. Notes 4, 116-118.

Sirjusingh, C., Kohn, L.M., 2001. Characterization of microsatellites in the fungal plant pathogen, Sclerotinia sclerotiorum. Mol. Ecol. Notes 1, 267269.

Slippers, B., Burgess, T., Wingfield, B.D., Crous, P.W., Coutinho, T.A., Wingfield, M.J., 2004. Development of simple sequence repeat markers for Botryosphaeria spp. with Fusicoccum anamorphs. Mol. Ecol. Notes 4, 675-677.

Stukenbrock, E.H., Banke, S., Zala, M., McDonald, B.A., Oliver, R.P., 2005. Isolation and characterization of EST-derived microsatellite loci from the fungal wheat pathogen Phaeosphaeria nodorum. Mol. Ecol. Notes 5, 931-933.

Tran-Dinh, N., Carter, D., 2000. Characterization of microsatellite loci in the aflatoxigenic fungi Aspergillus flavus and Aspergillus parasiticus. Mol. Ecol. 9, 2170-2172.

Walser, J.C., Sperisen, C., Soliva, M., Scheidegger, C., 2003. Fungus-specific microsatellite primers of lichens: application for the assessment of genetic variation on different spatial scales in Lobaria pulmonaria. Fungal Genet. Biol. 40, 72-82.

Wright, L.P., Wingfield, B.D., Crous, P.W., Brenneman, T., Wingfield, M.J., 2006. Isolation and characterization of microsatellite loci in Cylindrocladium parasiticum. Mol. Ecol. Notes 6, 110-112. 